Baimel, A., White, C.J.M, Sarkissian, H., \& A. Norenzayan (2021). How is analytical thinking related to religious belief? A test of three theoretical models. Religion Brain and Behavior, https://doi.org/10.1080/2153599X.2021.1878259

\title{
How is analytical thinking related to religious belief? A test of three theoretical models
}

\author{
Adam Baimel*1, Cindel J. M. White $^{2}$, Hagop Sarkissian ${ }^{3}$, \& Ara Norenzayan² \\ ${ }^{1}$ Department of Psychology, Health and Professional Development, \\ Oxford Brookes University, UK \\ ${ }^{2}$ Psychology Department, The University of British Columbia, Canada \\ ${ }^{3}$ Department of Philosophy, Baruch College, City University of New York, USA \\ *corresponding author contact information: abaimel@brookes.ac.uk
}

Author Contributions: A.B. assembled the relevant datasets, conducted all analyses and wrote the paper with C.W., H.S., and A.N.

Acknowledgements: This research was funded by a SSHRC Insight Grant (435-2014-0456) "The

Disclosure statements: All authors declare no conflicts of interests. 
The replicability and importance of the correlation between cognitive style and religious

29 belief has been debated. Moreover, the literature has not examined distinct psychological accounts

30 of this relationship. We tested the replicability of the correlation $(N=5284$; students and broader

31 samples of Canadians, Americans and Indians); while testing three accounts of how cognitive style

32 comes to be related to belief in God, karma, witchcraft, and to the belief that religion is necessary

33 for morality. The first, the dual process model, posits that analytical thinking is recruited in

34 overriding intuitions related to supernatural beliefs. The second, the expressive rationality model,

35 posits that analytical thinking is recruited in supporting already-held beliefs in an identity-

36 protective manner. And the third, the counter-normativity rationality model, posits that analytical

37 thinking is recruited to question beliefs supported by prevailing cultural norms. In Study 2, we

38 tested the replicability of our results in a re-analysis of published data. The association between

39 analytic thinking style and beliefs was replicated. We conclude that whereas the counter-

40 normativity rationality model was contradicted by the data, both the dual process and expressive

41 rationality models received varying degrees of empirical support, but neither model fully

42 accounted for all the patterns in the data.

\section{Keywords}

Religion; belief; analytical thinking; intuition 


\section{How is analytical thinking related to religious belief? A test of three theoretical models}

\section{Introduction}

What accounts for the emergence of religious beliefs in human minds? This question has long motivated research, and in recent years, a growing literature of interdisciplinary research offers explanations for the ubiquity of religious beliefs in terms of underlying motivational, cultural, and cognitive processes (e.g., Järnefelt, Canfield, \& Kelemen, 2015; Kay, Gaucher, McGregor, \& Nash, 2010; Norenzayan, 2016; Norenzayan et al., 2016). One of the key insights regarding the cognitive foundations of religious belief is the hypothesis that religious beliefs are partly rooted in interrelated intuitive cognitive biases, such as, mind-body dualism, teleology, and anthropomorphism (e.g., Atran \& Norenzayan, 2004; Barrett, 2007; Boyer, 2001). In support of this view, evidence is accumulating that these cognitive biases, working together with cultural learning processes, contribute to the proclivity for religious and supernatural beliefs (e.g., Banerjee \& Bloom, 2013; Järnefelt et al., 2015; Lindeman et al., 2015; Purzycki, 2013; Willard et al., 2020; Willard \& Cingl, 2017; Willard \& Norenzayan, 2013; for a recent review, see White et al., 2021). If religious beliefs are rooted in intuitively supported cognitive faculties, and analytical thinking can suppress or override intuitions relevant to supernatural thinking (e.g., Kelemen, Rottman, \& Seston, 2013), it follows that the strength of religious belief should be negatively related to analytical thinking. Extensive correlational research supports this inference and demonstrates that tendencies for overcoming the pull of one's intuitions is associated with lower religious belief (e.g., Study 1, Gervais \& Norenzayan, 2012; Pennycook, Cheyne, Seli, Koehler, \& Fugelsang, 2012; Shenhav et al., 2012). The most common of these findings are centered around a single measure of analytical thinking - the 'Cognitive Reflections Test' (CRT; Frederick, 2005). In the CRT, participants are presented with a series of math puzzles (e.g., "If it takes 5 machines 
705 minutes to make 5 widgets, how many minutes would it take 100 machines to make 100

71 widgets?") to which there is an intuitively compelling but wrong answer (i.e., 100 minutes), and a

72 correct answer (i.e., 5 minutes). Although simple in its design, this measure is reported to reliably

73 differentiate between those who tend to go with their 'gut' response and those who are willing to

74 reflect and override their 'gut' response (i.e., reason analytically) about the questions - even over

75 time and repeated tests, and controlling for cognitive ability (Stagnaro, Pennycook, \& Rand, 2018).

76 And in support of the hypothesis that religious belief is related to intuitive thinking styles, a meta-

77 analysis of 31 studies consisting of mostly North American participants $(N=15078)$, found that

78 CRT scores were inversely related to religious beliefs $(r=-.18, .95 \mathrm{CI}=[-.21,-.16]$; Pennycook,

79 Ross, Koehler, \& Fugelsang, 2016).

80 The dual-process model of religious belief

81 This correlational evidence forms the core of what can be called the dual process model of 82 religious belief (e.g., Norenzayan \& Gervais, 2013; Pennycook, Ross, et al., 2016; Shenhav et al., 83 2012). In this perspective, the human tendency for religious thinking emerges from the everyday

84 functioning of intuitive cognitive systems, whose output is constrained by careful, effortful 85 reasoning (for this distinction, see Evans \& Stanovich, 2013). In its strong version, this model 86 proposes that deliberation and questioning of human intuitions should consistently lead to the 87 rejection of belief. Thus, a core prediction of this model is that, all else being equal, it should be 88 more common that individuals reason their way out of their religious beliefs than it is for 89 individuals to reason their way into them.

90 However, one need not look deeply into the theological and philosophical record of treatises

91 on religious belief to realize that many a religious scholar have deeply reasoned their way into

92 (and/or in maintaining) their religious beliefs. Dating back to the $4^{\text {th }}$ and $5^{\text {th }}$ century, the careful and 
93 deeply analytical works of St. Augustine of Hippo, for example, remain a cornerstone of Christian

94 philosophically-reasoned arguments for believing in God (e.g., see De Cruz \& De Smedt, $2017^{1}$ ).

95 This raises an important question as to whether there are reliably detectable circumstances under

96 which analytical thinking can promote religious belief rather than dampen it.

97 The expressive rationality model of religious belief

98 Much like Augustine - who spent a great deal of time coming up with reasoned arguments

99 defending his conversion to Christianity (Jacoby, 2017) - individuals can be deeply motivated to

100 justify their previously-held commitments and beliefs and sometimes go to incredible lengths to

101 confirm their preconceptions (Nickerson, 1998). Although overriding one's intuitions might be a

102 good way to reason through all the available evidence, an alternative account suggests that

103 analytical thinkers might be even better than intuitive thinkers at finding ways to confirm their

104 biases regardless of the evidence. Indeed, the expressive rationality model holds that individuals

105 deploy their analytical thinking to justify previously-held beliefs and that they do so most

106 dramatically when these beliefs are strong indicators of their social affiliations (Kahan, 2017).

107 That is, rationality can be deployed to confirm already held beliefs as an identity-protective

108 strategy. For example, Kahan \& Stanovich (2016) demonstrated that belief in evolution in religious

109 and non-religious Americans is most different (i.e., polarized) amongst analytical thinkers from

110 either camp. In this view, while analytical thinking might lead nonreligious individuals to question

111 their core intuitions that the design of nature implies supernatural agency (Kelemen, 2004;

112 Kelemen et al., 2013; Rottman et al., 2016), the same analytical tendency leads religious

113 individuals to endorse supernatural agency with even greater conviction. Indeed, already-devoted

\footnotetext{
${ }^{1}$ Moreover, the entire philosophical tradition of natural theology has aimed at providing demonstrative arguments to prove God's existence and thus license great religious belief in the face of skepticism (Chignell \& Pereboom, 2020).
} 
114 analytical thinkers - like Augustine - might prove to be the deepest believers, or at the very least

115 no more or less believing than their intuitive and devoted counterparts. No work - yet - has directly

116 tested whether and how this model applies to belief in God.

117 The counter-normative rationality model

118 Moreover, an important limitation of the bulk of the research on the relationship between 119 analytical thinking and religious belief is that it has been conducted with mostly North American 120 and specifically majority Christian samples (with some important exceptions; e.g., studies of

121 Turkish Muslims found results of similar size and magnitude to those reported from American 122 samples; Yilmaz \& Saribay, 2016). To test the dual process model of religious belief cross123 culturally, Gervais et al. (2017) deployed the CRT and a measure of belief in God in a religiously124 diverse sample from 13 populations (e.g., Buddhists in Singapore, Hindus in Mauritius, Muslims 125 in the United Arab Emirates, and in secularized nations such as the Czech Republic). In aggregate, 126 Gervais et al. (2017) observed a relationship between analytical thinking and belief in God in the 127 direction predicted by the dual process model of belief; however, the average magnitude of the 128 effect was very small (i.e., an estimated average 2-point decrease on a 100-point scale of belief in 129 God with each additional correct answer on the CRT). While providing some cross-cultural 130 support for the dual process model of religious belief, the observed relationship between CRT and 131 belief was also found to be more strongly negative in more religious countries, and in a few places 132 - such as the UK, the observed relationship was reversed.

133 From this, Gervais et al. (2017) proposed a third possible account, which can be called the 134 counter-normative rationality model. This model says that the contents of our intuitions are not 135 just the output of evolved cognitive systems but also (at least in part) the output of culturally136 learned norms (Henrich, 2015). And thus, it may be that the observed effect of analytical thinking 
137 on religious beliefs is an expression of questioning the prevailing norm of religiosity in majority-

138 religiously affiliated cultures (i.e., where most of this research is conducted). In highly secularized

139 cultural contexts - questioning the norms might predict higher religious belief. In line with this,

140 Gervais et al. (2017) found that analytical thinking was weakly but positively related to belief in

141 God in a sample of students in the United Kingdom. However, Stagnaro, Ross, Pennycook, \&

142 Rand (2019), failed to replicate Gervais et al.'s positive association - in fact, they found the

143 typically sized negative correlation between CRT and belief in God in the United Kingdom in a

144 larger and broader sample of British adults. This additional data, however, does not necessarily

145 rule out the counter-normative rationality's account of the fluctuating magnitude of the

146 relationship as a function of varying levels of normative religiosity.

147 Testing the three models

148 The growing record of a robust negative correlation between analytical thinking and

149 religious belief has so far not adequately investigated the cognitive processes that account for this

150 relationship. Moreover, given recent failures to replicate the causal (i.e., experimental) effect of

151 induced analytical thinking on disbelief in God in high powered samples and preregistered designs

152 (Sanchez et al., 2017 and Camerer et al., 2018 failing to replicate Gervais \& Norenzayan, 2012,

153 Study 2; and Saribay et al., 2020 failing to replicate Shenhav et al., 2012) there is all the more

154 reason to aim for a better theoretical understanding of the underlying psychological processes and 155 moderators of the association between cognitive style and religious beliefs. Based on these 156 considerations, Study 1 had several goals.

157 First, we tested the dual process model of religious belief by assessing the replicability and 158 magnitude of the correlation between belief in God and cognitive style (measured in two 159 complementary ways - tendencies to think analytically and one's self-reported faith in intuition). 
160 In addition, and going beyond existing research, we examined whether the effect of cognitive style

161 extends to other types of religious and supernatural beliefs (i.e., the belief that religion is necessary

162 for morality, belief in karma, and belief in witchcraft). This is important, because the dual process

163 model predicts that all types of supernatural beliefs will be negatively correlated with analytic

164 cognitive style, whereas the expressive rationality and counter-normative rationality models do

165 not.

166 Second, we tested predictions from the expressive rationality model by examining the

167 interaction between cognitive style and political orientation in predicting varied beliefs.

168 Specifically, this model predicts that the relationship between analytical thinking and identity-

169 relevant beliefs such as belief in God and the belief that religion is necessary for morality will be

170 moderated by political orientation. These beliefs are both considered a hallmark of political

171 conservatism in North America (e.g., Haidt, 2012) and are more strongly endorsed by the

172 ideological right in many countries (Pew Research Center, 2020). The expressive rationality model

173 predicts that analytical thinking will be positively associated with these beliefs amongst politically

174 conservative individuals, but negatively associated with these beliefs among politically liberal

175 individuals - as analytical thinking is employed to strengthen existing commitments to identity-

176 relevant beliefs. This interaction thus resulting in widening differences in belief between liberals

177 and conservatives with increasing tendencies for analytical thinking. Otherwise, the expressive

178 rationality model really makes no clear predictions as to whether the relationship between

179 analytical thinking and non-identity-relevant supernatural beliefs (e.g., karma/witchcraft beliefs

180 among North Americans) will be similarly moderated by political orientation. Indeed, if the

181 relationship between analytical thinking and supernatural beliefs results entirely from the

182 dynamics of identity-protective motivated reasoning as would be proposed by a strong version of 
183 the expressive rationality model, then analytical thinking would be unrelated to non-identity-

184 relevant supernatural beliefs. We test for all these possibilities in Study 1.

185 Third, we tested the counter-normative rationality model in a novel way, by examining the

186 direction of the correlation between cognitive style and belief in counter-normative supernatural

187 beliefs - in karma and in witchcraft in samples where these beliefs have markedly different

188 normative status. Specifically, we tested the predictions of counter-normative rationality model

189 that: (1) among majority Hindu Indians (where karmic belief is more normative ${ }^{2}$ ) analytical

190 thinking should be negatively related to karma beliefs; but, (2) among North Americans (where

191 karmic belief is less normative), analytical thinking should be positively related to karma beliefs.

192 Witchcraft beliefs, however, being less normative in both samples, are predicted by this model to

193 be positively (or less strongly negatively) related to analytical thinking. In sharp contrast, the dual

194 process model predicts that these associations will be consistently negative.

195 Finally, in Study 2, we tested the replicability of the some of the focal results obtained in

196 Study 1 in data that was not collected by our team, through a re-analysis of two previously

197 published and openly-accessible datasets (Gervais et al., 2017; Stagnaro et al., 2019).

198 In both studies, the hypotheses are compared and contrasted in a Bayesian framework that

199 enabled us to determine the relative probabilities with which the data provide evidence in support

200 (or against) the specific predictions of these three models. In doing so, we (1) provide further tests

201 of the replicability of the association between analytical thinking and religious beliefs, in terms of

202 its magnitude and association in previously studied and understudied cultural contexts, and (2)

\footnotetext{
2 The Indian participants in Study 1 were roughly 75\% Hindu (the rest of participants were mostly Christian or Muslim); and although karmic beliefs are more strongly endorsed by Indian Hindus than other Indian subpopulations, they are still commonly endorsed by Indian Christians and Muslims (White, Norenzayan \&Schaller, 2019).
} 
203 also move beyond documenting the association, to test three distinct psychological accounts of the

204 association between cognitive style and religious beliefs.

\section{Study 1}

In Study 1, we tested the predictions of three psychological accounts of the relationship

207 between analytical thinking and religious beliefs in four samples (undergraduate students at a

208 Canadian university, and broader non-student samples of Canadians, Americans, and Indians).

209 The dual process model of belief predicts that analytical thinking (i.e., greater cognitive

210 reflection and less faith in intuition) will be negatively related to all forms of supernatural beliefs

211 across all samples. The expressive rationality model of belief predicts that (1) the relationship

212 between analytical thinking and identity-relevant supernatural beliefs (e.g., belief in God, and

213 belief that religion is necessary for morality) will be moderated by political orientation (i.e., such

214 that the association is negative for liberals and positive for conservatives), (2) that political

215 orientation will not moderate these associations in the case of non-identity relevant supernatural

216 beliefs and/or that analytical cognitive style will be unrelated to endorsement of non-identity

217 relevant beliefs. The counter-normative rationality model, on the other hand, predicts that

218 analytical thinking will be positively related to endorsement of counter-normative supernatural

219 beliefs.

\section{Methods}

221 Sample

222 To test these predictions, we identified datasets that we had previously collected which

223 included the relevant variables to examine the association between cognitive style and varied

224 religious/supernatural beliefs. A total of 9 datasets were identified $(N=5284$; see Table $\mathrm{S} 1$ for

225 sample details of each dataset). Participants were: undergraduate students sampled from the 
226 University of British Columbia Psychology Department's Human Subject Pool; a national sample

227 of Canadians; two samples of majority Hindu Indians (one sample recruited from Amazon's

228 Mechanical Turk and a broader national sample recruited by an online market research company),

229 and a broad sample of majority Christian Americans (recruited from Amazon's Mechanical Turk).

230 All measures, data analytic choices, and data exclusions are fully disclosed in this article; and

231 materials, data and analysis scripts are available at https://osf.io/hpw38/.

232 Materials

233 The presence/absence of the focal measures in each data set are presented in Table S2.

234 Summary statistics of all focal measures are presented in Table S3 and correlations by sample in

235 Table S4, and distributions of responses plotted in Figure S1.

236 Measures of belief

237 Across the datasets in Study 1, belief in God was measured on different response scales (5-

238 and 7-point scales). To allow for comparison across response scales, belief in God was linearly

239 recoded to a 0 (minimum belief) to 100 (maximum belief) scale. This type of rescaling was

240 beneficial for two reasons. First, it had the benefit of making all effect size estimates across Study

2411 and Study 2 directly comparable (as all examined datasets now employed a 0 to 100 response

242 scale to measure belief endorsement). Second, alternative rescaling strategies like standardizing

243 responses within datasets would cancel out between dataset mean differences, effectively

244 eliminating the benefits of partial pooling that result from generating estimates and predictions

245 using mixed-effect regression models as we do in our analyses.

246 In four of the datasets, the belief that religion is necessary for morality was assessed. This

2475 -item scale asked participants to rate the extent to which they agree with items such as, "Generally

248 speaking, people need religion to be morally good", and "An individual who does not believe in 
249 God cannot lead a moral life" ( $\alpha=.96$; full scale included in supplemental, Table S5). Across

250 datasets, responses were coded on varying response scales (6- and 7- point scales). As above,

251 responses were recoded on to a 100-point scale. The belief that religion is necessary for morality

252 is prevalent across cultures (Pew Resarch Center, 2020) and known to be particularly polarizing

253 between North American conservatives and liberals (Pew Research Center, 2014).

254 Belief in karma was assessed using either the 16-item or 4-item version of a karmic belief

255 scale (White, Norenzayan, \& Schaller, 2019). This scale assesses belief in karma with items such

256 as, "Karma is a force that influences the events that happen in my life", and "When people

257 experience good fortune, they have brought it upon themselves by behaviour in a past life". This

258 scale showed good internal consistency across samples $(\alpha \mathrm{s}=.90-.93)$.

Belief in witchcraft was assessed using a 7-item scale $(\alpha s=.84-.91$ across samples; e.g.,

260 "People can harm others with supernatural power, e.g., by cursing or casting spells on people", 261 and "If other people have had bad thoughts towards you, it can make you sick"). These items have 262 some overlap with (but are not identical to) previously examined measures of paranormal beliefs 263 that have been reported to be negatively correlated with analytical thinking (Pennycook et al., 264 2012).

265 Measures of cognitive style

266 The Cognitive Reflection Test (Frederick, 2005) is a three-item measure $(\alpha=.75$ across

267 samples) designed to assess capacities and general tendencies for inhibiting intuitive responses 268 and thinking more analytically. The test's three questions have an intuitively compelling (but 269 wrong) answer (e.g., "If a bat and a ball cost $\$ 1.10$, and the bat costs $\$ 1.00$ more than the ball, how 270 much does the ball cost?"). Individuals who tend not to reflect often give the answer "10 cents" 271 (the modal response). Individuals who do make the effort to reflect are more likely to arrive at the 
272 correct answer, "5 cents". Correct responses are summed, and the total score serves as an index of

273 analytical thinking. This test is commonly used in assessing the association between analytical

274 thinking and religious belief (e.g., Pennycook, Ross, Koehler, \& Fugelsang, 2016).

275 The Faith in Intuition subscale of the Rational Experiential Inventory (Pacini \& Epstein,

276 1999) was included in these datasets as a measure of intuitive cognitive style. This 20-item self-

277 report measure $(\alpha=.96)$ asks participants to indicate their agreement with a series of statements

278 reflecting an explicit preference for not overthinking and trusting in one's intuitions (e.g., "I like

279 to rely on my intuitive impressions", and "I believe in trusting my hunches"). The inclusion of this

280 measure of intuitive thinking style allowed us to test the robustness of the hypothesized association

281 between cognitive style and religious belief. Responses were on varied response scales (5- and 7-

282 point scales) and were first rescaled on to a 0 to 1 scale for comparison and then reverse scored

283 such that higher scores indicated less faith in intuition to ease comparisons between this measure

284 and the CRT.

285 Political Orientation

286 Political orientation was measured across all datasets with a single item that asked 287 participants to indicate whether they were very liberal (1) to very conservative (7) on a Likert288 scale.

\section{Results}

\section{Analytical Strategy and Predictions}

291 Our analytical strategy was not pre-registered. As such, our focal regressions include only

292 variables that are directly relevant to testing the predictions of the dual process, expressive 293 rationality and counter-normative rationality models of religious beliefs (i.e., measures of belief, 294 political orientation, and identifiers for sample and dataset). The publicly available datasets include 
295 additional demographic variables (age and sex); and we note that the pattern of results reported 296 here remain unchanged when demographic controls are added to the models. We actively 297 encourage those interested in considering the relationship between these additional variables and 298 our focal predictors to make use of our compiled data.

All analyses were conducted in $R$ (R Core Team, 2017). Bayesian mixed-effect linear 300 regression models were executed using the brms (Bürkner, 2017) compiler for RStan (Stan 301 Development Team, 2017). Model summary tables were generated with sjPlot (Lüdecke, 2018). 302 Beliefs were modelled with a random-intercept for dataset (unless data was only available from a 303 single source, in which case no random-intercept was included). Priors were set as weakly304 regularizing: fixed effects $\sim \operatorname{Normal}(0,1)$; and for variance components for varying effects $~$ 305 Exponential(1); which help to minimize overfitting the model to the data in the estimation process 306 (McElreath, 2015, p. 393; Purzycki, Pisor, et al., 2018).

307 All predictions were tested in models that took one of two forms. The first examined the 308 main effect of analytical thinking on beliefs within each sample by including an interaction term 309 between sample and the measure of analytical thinking (CRT or reverse coded faith in intuition).

310 The second tested for the moderating effect of political orientation $(1=$ very liberal, $7=$ very 311 conservative; standardized) on the relationship between analytical thinking on belief in each 312 sample. The four belief outcomes (belief in God, belief that religion is necessary for morality, 313 belief in karma and belief in witchcraft), two measures of cognitive style (CRT and faith in 314 intuition), and two model forms resulted in 14 model specifications all of which were run for 2000 315 iterations (1000 warmup) across four sampling chains that converged across all specifications $(\hat{R} S$ $316<1.01)$. For interested readers, the summaries of all 14 regressions are presented in the 317 supplemental materials: belief in God (CRT - Table S6; Intuition - Table S7), belief that religion 
318 is necessary for morality (Table S8), belief in karma (CRT - Table S9; Intuition - Table S10) and

319 belief in witchcraft (CRT - Table S11; Intuition - Table S12). In the main text, we summarize the

320 results of these models by extrapolating and making predictions from the posterior distributions of

321 the estimated contributions of analytical thinking to belief.

322 In what follows, the reported regression coefficients are the means of the posterior

323 distributions for each parameter estimated by the Bayesian models and can be interpreted as one

324 would a regression coefficient in a frequentist framework. The uncertainty around these point

325 estimates are described by the highest density intervals (95\% HDIs). These intervals indicate the

326 range of values that make up the $95 \%$ most credible estimates of the parameter in the posterior

327 distribution. By more closely examining the posterior distributions of the model estimated

328 associations of analytical cognitive style and supernatural beliefs in varied contexts (between

329 samples; and within samples in more or less politically conservative individuals), we assessed

330 the extent to which these data support the predictions of the dual process, expressive rationality,

331 and counter-normativity rationality models of belief. Put simply and to summarize:

332 1. The dual process model parsimoniously predicts that all associations between analytical

333 cognitive style and supernatural beliefs will be negative.

3342 . The expressive rationality model predicts that:

335 a. The association between analytical cognitive style and identity-relevant

336 supernatural beliefs (i.e., belief in God and belief that religion is necessary for

337 morality) will be moderated by political orientation such that the association will

338 be positive in more conservative individuals and negative in more liberal

339 individuals. 
b. The association between analytical cognitive style and non-identity relevant supernatural beliefs (i.e., belief in karma and belief in witchcraft among North Americans) will not be moderated by political orientation - and that the main effect of analytical cognitive style on these beliefs will be largely zero.

\section{Bayesian regression model evaluations}

As a first step to assessing which of these models better accounts for the data - we evaluated our regressions with the loo package to estimate out-of-sample prediction accuracy using 'leave-one-out' (loo) cross-validation (Vehtari et al., 2017). The results (see Table 1)

351 suggest that by and large the regressions that included the analytical thinking by political

352 conservativism interaction (in line with the expressive rationality model) had greater predictive 353 performance than regressions that predicted belief only from cognitive style in each sample (i.e.,

354 those in line with the dual process model). This indicates that when predicting religious and 355 supernatural beliefs, cognitive style alone is a relatively poorer input than knowing one's 356 political orientation and tendencies for analytical thinking. Importantly, these evaluations adjust

357 for differences in the number of parameters between models suggesting that the better predictive 358 performance of the regressions in line with the expressive rationality model is not owed to there 359 being more predictors in the regressions testing the interaction. However, these evaluations do 360 not test for the predicted differences regarding the directionality of the estimated association 361 between cognitive style and belief. Given the relatively greater performance of the regressions 362 that included the expressive rationality model's predicted interaction, we next employed the 
363 parameter estimates from these regressions to specifically test the directional predictions of the

364 three focal models.

365 Analysis 1: Dual Process Model

366 Figure 1 presents the estimated posterior distributions of the association between

367 analytical thinking (CRT and reverse-scored faith in intuition) and beliefs in all samples at (1)

368 average political orientation, (2) in more liberal (-1 SD) and (3) in more conservative individuals

369 (+1 SD). For the most part, the estimated association is robustly negative for both measures of

370 analytical thinking, varied kinds of belief, in different samples, and at different levels of political

371 orientation. This provides consistent and clear support for the dual process model. Indeed, the

372 posterior probability that at average liberalism-conservatism (i.e., 'controlling for political

373 orientation') analytical thinking is negatively associated with belief drops below .98 (i.e., highly

374 probable) only in a single case (the association between witchcraft beliefs and intuition in

375 Indians where the posterior probability $=.87$, which still mostly supports the dual process model; 376 see Table 2).

377 Analysis 2: Expressive-rationality model

378 Returning to Figure 1, the magnitude of the association between analytical thinking and

379 belief is observably moderated by political orientation, but not in the way that the expressive

380 rationality model necessarily predicts (for precise estimates and intervals see Table 2). When

381 comparing more liberal individuals (-1 SD) to more conservative individuals (+1 SD) we do not

382 find that the estimated associations reverse directions for identity-relevant beliefs (belief in

$383 \mathrm{God} /$ belief that religion is necessary for morality). Moreover, as already noted, we do not find

384 that analytical thinking is unrelated to non-identity relevant belief sets (belief in karma and

385 witchcraft). In stark contrast to the model's predictions, it is a non-identity relevant belief that 
shows the greatest probability of being positively associated with analytical thinking (belief in witchcraft in Americans, and also Indians; with most of the more conservative distribution crossing the dashed zero line). However, what we do find is that the magnitude of the associations are more often than not reduced in more conservative as compared to more liberal 390 individuals. Indeed, in all but two cases ${ }^{3}$, the posterior probabilities that the association is 391 stronger in more liberal-leaning individuals than it is in more conservative-leaning individuals 392 are greater than .94 (see Table 2).

To follow this up and further unpack the analytical thinking by political orientation 394 interaction, we generated and plotted the predictions made by our regressions at each level of 395 political orientation (Figure 2). In so doing, we find that although we see little support for the 396 prediction of the expressive rationality model that there will be a positive association with belief 397 among conservatives (as summarized in Figure 1 and Table 2), we do find that the patterns of 398 belief are at least somewhat in line with the expressive rationality model. Indeed, the predicted 399 spreading interaction resulting from a positive association of belief and analytical thinking in 400 more conservative individuals and a negative association in more liberal individuals is evident in 401 a few instances (e.g., belief in God in Students) but a spreading interaction also appeared in what 402 we had considered non-identity relevant supernatural beliefs (e.g., belief in witchcraft among 403 Americans). And although this spreading interaction was not consistent across beliefs or 404 samples, it was reliably the case that variance in predicted belief is greater at high analytical 405 thinking than at low analytical thinking (i.e., the regression lines are more tightly clustered 406 together at low analytical thinking than at high analytical thinking). What this suggests is that

\footnotetext{
${ }^{3}$ These are the same two cases in which LOO model evaluation indicated no evidence for difference in predictive performance between regressions with and without the conservatism by analytical cognitive style interactions.
} 
407 without knowing one's political orientation, the extent of one's analytical thinking tendencies is

408 a relatively poor predictor of supernatural beliefs. This provides some further indication as to

409 why the regression models that included the analytical thinking by political orientation

410 interaction made more accurate predictions than models of just the main effect of analytical

411 thinking in each sample (Table 1). Moreover, Figure 2 clearly demonstrates that the negative

412 association between analytical thinking and varied beliefs is strongest in the most liberal

413 participants (with the steepest slopes), and the weakest (but only rarely positive) in the most

414 conservative participants. While these results do not exactly match the predictions of the

415 expressive rationality model, they nonetheless suggest that identity-protective processes are a

416 factor; thus it is important for future research to avoid simply averaging across political

417 orientations.

418 Analysis 3: Counter-normative rationality model

419 The identified clear support for the dual process model effectively demonstrates that the 420 predictions of the counter-normative rationality model are not supported in this data. We did not

421 find that endorsement of counter-normative supernatural beliefs were positively related to

422 analytical thinking (i.e., belief in karma and witchcraft were negatively associated with analytical

423 thinking in both the North American and the Indian samples, despite cultural differences in

424 karma's normativity).

\section{Discussion}

426 The results of Study 1 replicate previously reported findings that analytical thinking is 427 negatively correlated with religious and supernatural beliefs in a large and diverse sample. Our 428 results provide further evidence that this association, despite its small magnitude, extends to

429 several types of religious and supernatural beliefs. Moreover, tendencies for analytical thinking 
430 (as measured by the Cognitive Reflection Test) and placing faith in one's intuition (as measured

431 in a self-report scale) converged in predicting religious and supernatural beliefs. Taken together,

432 this provides evidence that the association between cognitive style and religious belief is robust to

433 two different cognitive measures. Indeed, while the CRT reliably measures tendencies for

434 overriding one's intuitions, it has somewhat surprisingly been demonstrated to be a relatively poor

435 indicator of individual differences in reliance on intuitions (Pennycook, Cheyne, et al., 2016). And

436 thus, the growing body of work that employs the CRT in examining the relationship between

437 analytical thinking that and belief in God is better understood as documenting the negative

438 association of analytical thinking and belief, and not necessarily the complementary positive

439 association of intuition. Here, the consistently observed negative relationships of (reverse scored)

440 self-reported faith in intuition speaks to this inverse relationship - that a reliance on one's intuitions

441 is likewise related to belief.

442 In addition to this complementary relationship between intuition and analytical thinking in

443 predicting belief in God, our results provide evidence that these relationships extend to other types

444 of religious and supernatural beliefs. Analytical thinking was found to be negatively related to

445 belief in karma and witchcraft across samples that varied considerably on whether these beliefs

446 are culturally normative, and even to cross-culturally prevalent beliefs that religion is necessary

447 for morality. These consistently negative associations disconfirm the predictions of the counter-

448 normative rationality model that analytical thinking might be employed to question culturally

449 normative beliefs - and provide additional clear support for the dual process model of belief.

450 While the dual process model of belief was tested in various ways and received support,

451 the results revealed an important limitation of this model in explaining belief. Across diverse belief

452 types and samples, the negative association between analytical thinking and belief was found to 
453 be weaker in more conservative individuals. The dual-process model is silent about this pattern,

454 and it is particularly striking and non-obvious, given that more politically conservative individuals

455 are reported to rely more heavily on their intuitions, and are generally more religious (Deppe et

456 al., 2015; Haidt, 2012; Nail et al., 2009; Pew Research Center, 2017). Given that the relationship

457 between analytical thinking and belief in God, for example, is reported to be greater in more

458 religious nations (Gervais et al., 2017), it might be expected that the association within-samples

459 would be greater amongst more religious sub-samples (i.e., more conservative-leaning individuals)

460 than less religious sub-samples (i.e., liberal-leaning individuals). And thus, if anything, the dual

461 process model, with some extra tweaking, would make the prediction that, if there was going to be

462 a difference in the association amongst conservative and liberal individuals, it would be larger (not

463 smaller or reversed) amongst conservatives - a pattern that was not found in our data.

464 Some, but not all, of our results can instead be accounted for by the expressive rationality

465 model, which argues that analytical thinking is employed not to override intuitions but rather to 466 engage in identity-confirming motivated reasoning (Kahan \& Stanovich, 2016). While some of the

467 predictions made from our regression models do generate the spreading interaction predicted by

468 the expressive rationality model for identity-relevant beliefs (e.g., belief in God predicted by the

469 CRT in an undergraduate student sample), we also see some evidence of this spreading interaction

470 in predictions of non-identity relevant beliefs (e.g., belief in witchcraft as predicted by faith in

471 intuition in Americans and Indians). This latter result not being directly predicted by the expressive

472 rationality model as formulated here. That being said, our data cannot directly address whether

473 witchcraft beliefs are identity-relevant to conservatives and liberals in India or the USA. Even

474 though we see evidence of the spreading interaction in both samples in Figure 2, witchcraft beliefs

475 are more strongly correlated with political conservatism in Indians $(r=.34)$ than in Americans $(r$ 
$476=.06)$; suggesting that different processes may be at play here in these two samples, or even that

477 these results have little to do with identity-protective cognitions. And yet more consistently, what

478 we find is not a spreading interaction resulting from a positive association between analytical

479 thinking and belief in more conservative individuals and a negative association in more liberal

480 individuals but rather a reduction in the magnitude of the association in more conservative as

481 compared to more liberal individuals.

482 If there is one thing that is abundantly clear in our data, it is that we find no support for the

483 predictions of the counter-normative rationality model. Otherwise, our data support the dual

484 process model, but with the important caveat that the magnitude of the association between

485 analytical thinking and diverse supernatural beliefs are consistently reduced (and in some instances

486 reversed in direction) amongst more conservative individuals than amongst more liberal

487 individuals. Before considering whether this provides evidence for the expressive rationality

488 model, we turn first, in Study 2, to testing the expressive rationality model in two additional

489 datasets in which only the main effect of analytical thinking has been previously reported. The

490 results of Study 1 provide sufficient impetus for researchers to look more closely at the association

491 between cognitive style and belief at different levels of political orientation, rather than merely

492 controlling for it.

493

\section{Study 2}

494

In Study 2, we tested the predictions of the expressive rationality model of religious belief

495 in two additional openly-accessible datasets from recently published papers testing the dual

496 process model of belief in diverse samples. The first dataset (Gervais et al., 2017) examined the

497 relationship between belief in God and scores on the Cognitive Reflection Test in 13 samples.

498 Their results demonstrated that the relationship between belief in God and CRT scores is (1) small; 
499 (2) variable across cultures; and (3) that the magnitude of the effect is reduced in less religious 500 nations. Interestingly, these authors reported a surprising reversal: a small positive correlation 501 between belief in God and analytical thinking in the United Kingdom. The second dataset 502 (Stagnaro, Ross, Pennycook, \& Rand, 2019) examined the relationship between belief in God, 503 supernatural beliefs (measured more broadly) and the Cognitive Reflection Test in India and the

504 United Kingdom, controlling for political orientation (as a direct attempt to replicate the surprising 505 reversal reported by Gervais et al., 2017). In India and the United Kingdom (speaking to the non506 replicability of the reported reversal from Gervais et al. 2017), Stagnaro et al. (2019) reported a 507 negative correlation between belief in God and analytical thinking that was comparable in size to 508 that expected by the meta-analytic estimates of the relationship. Neither of these papers, however, 509 considered the potential moderating effect of political orientation in the relationship between 510 analytical thinking and religious belief. Using their openly accessible data, we tested the 511 predictions of the expressive rationality model of belief in the samples from these datasets where 512 political orientation was assessed (Gervais et al., 2017: Australia, China, Czech Republic, India, 513 Mauritius, Netherlands, and Singapore; and Stagnaro et al., 2019: United Kingdom). Critically, we 514 treat these analyses as an entirely exploratory attempt to replicate the focal results in Study 1 in a 515 broader sample. We made no strong or specific a priori claims as to having insight into the 516 dynamics linking political orientation and religious belief in these diverse cultural settings.

\section{Methods}

The published datasets were retrieved from the Open Science Framework: Gervais et al. 519 (2017) - https://osf.io/v53c4/; Stagnaro et al. (2019) - https://osf.io/jb2mr/). For full sample details, 520 interested readers should refer to their published papers. In both datasets, not all samples included 521 a measure of political orientation and thus we selected only those samples that did. These 
522 exclusions left us with 1192 individuals from 7 countries (Australia, China, Czech Republic, India,

523 Mauritius, Netherlands, and Singapore) from the Gervais et al. (2017) dataset; and 523 individuals

524 from the United Kingdom from Stagnaro et al. (2019) Distribution of responses to the focal

525 measures used in this re-analysis are presented in Figure S2. Our scripts for the re-analysis of these 526 datasets are available at https://osf.io/hpw38/.

527 Measures

In Gervais et al. (2017), belief in God was measured on a 0 to 100 (max belief) scale, 529 analytical thinking was assessed using the 3-item Cognitive Reflection Test (Frederick, 2005), and 530 political orientation was assessed with a single item ("Would you consider yourself more liberal 531 or conservative? [ 1 = very liberal; 7 = very conservative]. In Stagnaro et al. (2019), belief in God 532 was measured on a 0 to 100 (max belief) scale, analytical thinking was assessed using a 7-item 533 Cognitive Reflection Test (Thomson \& Oppenheimer, 2016), and political orientation was 534 assessed with two items: “On social issues I am..." and "On economic issues I am..." [1 = strongly 535 liberal to $5=$ strongly conservative]. These two items were strongly positively correlated, $r(521)$ $536=.73[.69, .77], p<.001$ and we took their average as an index of political conservatism. Stagnaro 537 et al. (2019) also measured supernatural belief using the 6-item revised-Supernatural Belief Scale 538 (Jong \& Halberstadt, 2016). For all analyses, political orientation was centered (negative values = 539 more liberal; positive values = more conservative)

$540 \quad$ Analytical Models

541 Analyses were conducted using the same software as in Study 1. Beliefs were modelled 542 using Bayesian mixed-effect linear regressions as conducted in Study 1. For the re-analysis of the 543 Gervais et al. (2017) dataset a random intercept for sample was included (7 countries) in addition 544 to a random slope by country for the effects of CRT, political orientation and their interaction - to 
545 allow all effects to vary across samples. The UK data from Stagnaro et al (2019) were modelled 546 using Bayesian linear regressions (i.e., with no random effects). Priors were set as uninformative 547 and weakly-regularizing: fixed effects $\sim \operatorname{Normal}(0,1)$; variance components for varying effects $\sim$ 548 Exponential(1); and for the covariance structure of varying effects $\sim$ LKJ(4); (McElreath, 2015, p. 549 393; Purzycki, Pisor, et al., 2018).

\section{Results}

Reproducing the focal results and support for the dual process model reported by Gervais 552 et al. (2017) and Stagnaro et al. (2019), across all models, analytical thinking (CRT) was negatively 553 related to religious belief controlling for political orientation (model summaries presented in the 554 supplemental materials; Table S13). When holding political orientation constant at zero (i.e., 555 amongst political centrists), these models predict varying magnitudes of belief reduction amongst 556 those who respond correctly to all CRT items: 3.93 points out of 100 (Gervais et al. data; belief in 557 God), 10.92 points (Stagnaro et al. data; belief in God), and 16.02 points (Stagnaro et al. data; 558 supernatural belief).

As observed in Study 1, however, the estimated effect of CRT on belief was moderated by 560 political orientation across models. The posterior distributions of regression coefficients at varied 561 levels of political orientation are plotted in Figure 3 (and precise estimates presented in Table 3). 562 In all three cases, we find that the association is more strongly negative in more liberal leaning 563 participants than in more conservative leaning participant. That being said, the magnitude of the 564 effect remains small, and is less clearly differentiated in Gervais et al.'s (2017) more broadly cross565 cultural dataset. Moreover, we again find only a slight indication of a reversal of the direction of 566 the association in the conservative leaning individuals as predicted by the expressive rationality 567 model - and rather that the posterior distributions of the estimated association are more closely 
568 centered around zero. As in Study 1, this analysis provides evidence that the predictions of the

569 dual process model of belief holds more for liberals than conservatives. And as in Study 1, although

570 we find no clear support for the expressive rationality models' predicted reversal of the association

571 in conservatives; we do find that the already small negative association approaches 0 in more 572 conservative individuals.

\section{Discussion}

In Study 2, we further tested the predictions of the expressive rationality model of belief in

575 two additional cross-cultural datasets. We find that in both of these datasets - the negative

576 relationship between CRT and religious belief predicted by the dual process model of belief was

577 to some extent stronger in increasingly liberal-leaning individuals. However, contrary to the

578 prediction of the expressive rationality model, the association between analytic thinking and 579 religious belief in conservative-leaning individuals was largely flat - it was not positive. These 580 results provide further evidence that the contributions of CRT to religious belief can sometimes be 581 just as "fickle" (Gervais et al., 2017) within cultures as they may be between them. While Stagnaro 582 et al. (2019) demonstrated a negative relationship controlling for political orientation, our analyses 583 demonstrate that the relationship is largely reduced to zero with greater political conservatism. 584 And while this result does not provide strong evidence for the expressive rationality model of 585 belief, in the general discussion we consider this evidence, in tandem with the results of Study 1, 586 by returning to our focal question of "how" is analytical thinking related to religious and 587 supernatural beliefs.

\section{General Discussion}

How is analytical thinking related to religious belief? To answer this question, in two

590 studies we tested competing predictions derived from three accounts about the contributions of 
591 cognitive style to religious belief (one of which, the counter-normative rationality model, went 592 completely unsupported). As predicted by the dual process model of religious belief, we found that 593 analytical thinking is robustly related to religious belief in the predicted negative direction, in large 594 culturally diverse samples, for two distinct measures of analytic thinking (cognitive reflection and 595 faith in intuition), and for several types of religious beliefs (i.e., belief in God, that religion is 596 necessary for morality, in karma, in witchcraft). Nevertheless, the dual process model's limitations 597 in accounting for religious belief were apparent in the estimated small effect size and the 598 consistently observed interaction of analytical thinking and political ideology, which is not 599 obviously predicted by this model. And thus, the pattern of our results also fit to some extent with 600 the predictions of an alternative account - the expressive rationality model of belief - that holds 601 that analytical thinking is employed to sustain one's already held commitments, particularly those 602 emblematic of social identities. However, this model had its limitations too; from the perspective 603 of the expressive rationality model, (1) the negative association between analytic thinking and 604 religious belief should reverse for political conservatives, (2) the main association should 605 disappear once the interaction with political ideology is taken into account, and (3) analytical 606 thinking should only be associated with identity-relevant supernatural beliefs. These predictions 607 received inconsistent support. The main effect often remained even after accounting for the 608 interaction with political ideology; moreover, the predicted reversal (to a positive relationship 609 between analytic thinking and religious/supernatural belief) for conservatives did not materialize 610 in most of our samples. Instead, we consistently observed that rather than reversing in direction, 611 the size of the association weakened or became zero among conservatives. And contrary to the 612 expressive rationality model, we find that this weakening of the effect in more conservative 613 participants compared to more liberal participants occurred in both identity-relevant (belief in God, 
614 belief that religion is necessary for morality) and not-obviously identity-relevant beliefs (belief in 615 witchcraft in both Americans and Indians).

616 One way to interpret these results is to take them as evidence for a "weak" version of the

617 expressive rationality model that makes the prediction that analytical thinking will only be 618 negatively correlated with religious beliefs amongst more politically liberal individuals, while

619 being largely unrelated to belief amongst more politically conservative individuals. But it is not 620 directly obvious why identity-protective cognitions would be less involved in maintaining 621 religious and supernatural beliefs in the typically more religious sub-samples of our datasets (i.e., 622 conservative-leaning individuals). Another way to explain these results might be to make the 623 prediction that if we had more data from the most liberal and most conservative individuals, we 624 might have observed stronger evidence for the predicted reversal and the spreading interaction. 625 Testing this prediction is one clear way forward for research of this kind. But yet, an altogether 626 different explanation arises from considering the relative contributions of 'cognition' and 627 'culture' in predicting religious and supernatural beliefs.

628 A recent review of the empirical evidence (White et al., 2021) and a pre-print of a study 629 that employs a nationally-representative sample of Americans (Gervais et al., 2019) provide 630 evidence that analytical cognitive style is a robustly weaker predictor of religious and 631 supernatural beliefs than is growing up with caregivers who consistently demonstrated their 632 religious commitment (i.e., religious credibility enhancing displays; Lanman \& Buhrmester, 633 2016). What our results might suggest is that high enough cultural exposure to religion - as might 634 be more likely in more conservative individuals than in liberals - leaves little room for cognitive 635 style to have sway over the extent to which one endorses religious and supernatural beliefs. This 636 perhaps explains the fairly consistent reduction in the association between analytical thinking 
637 and belief in politically conservative individuals. If this is the case, then the dynamics at play

638 might have little to do with identity-protective cognition; instead, political orientation in our

639 datasets is perhaps acting as a proxy-measure for cultural exposure to religion. In support of this

640 view, Gervais et al. (2019) found that analytical thinking only predicted supernatural beliefs in in

641 those with relatively lower cultural exposure to religion. That being said, this alternative

642 explanation does little to account for the cases, particularly at the extremes of political

643 orientation, in which some of our models do indeed predict patterns in line with the expressive

644 rationality model.

645 Taken together, it is clear that neither the dual process nor the expressive rationality model

646 can fully account for all of the observed data. And importantly, neither of them (as they are

647 currently posited) seem fully equipped to deal with how intuition and/or analytical thinking may

648 or may not be implicated in 'religious and supernatural belief' (broadly construed) in a variety of

649 different cultural contexts. Although it is the counter-normative rationality model that went

650 entirely unsupported - it is the dual process model of belief, given its broad predictive potential,

651 that requires the most re-calibration. The dual process model of belief as it is currently formulated

652 provides no explanation for the observed within-sample heterogeneity in how the strength of the

653 association between analytical thinking and beliefs depends on political orientation. And thus, it

654 has the most difficulty accounting for some observations, like those reported here, that the

655 relationship between cognitive style and belief is sometimes (though not always) moderated by

656 political orientation. The evidence suggests, in part, the operation of motivated reasoning processes

657 in justifying both believing and not believing. Importantly, the current analyses show that the dual

658 process and expressive rationality models as applied to religious belief likely have independent

659 explanatory value (despite their shortcomings) and are not necessarily incompatible theoretical 
660 accounts. The pattern of results is thus consistent with the idea that at least two independent,

661 interacting psychological processes are at play, one guided by the intuitiveness of supernatural

662 beliefs consistent with a dual process account, the other guided by motivated reasoning consistent

663 with the expressive rationality account. And from what we have learned from other recent work in

664 this area (Gervais et al. 2019), it is all together possible that the extent to which either or both of

665 these processes contribute to belief may covary in meaningful ways with a third psychological

666 mechanism - cultural learning driven by social exposure to religion.

667 Given the expressive rationality's model explanatory power in other domains (e.g., climate

668 change beliefs; Kahan et al., 2012), at least where it has been tested (i.e., in nationally

669 representative samples of Americans) - it remains an open question, as to whether our results would

670 look different with access to a broader, fully representative sample. Our results demonstrate some

671 cross-culturally recurrent patterns in predicting diverse religious and supernatural beliefs. But of

672 course, a clear way forward in unpacking the contributions of cognitive style to belief is to continue

673 broadening the scope of these types of investigations, in more diverse cultures - but also more

674 broadly within cultures. On this front, future work should broaden the scope of the content of

675 examined supernatural beliefs to include those that might also be more representative of both

676 liberals and conservatives in their investigations of the cognitive mechanisms supporting

677 supernatural beliefs. For example, belief in astrology, horoscopes, and the Tarot is high amongst

678 North American youth, consistent with other secularized corners of the world (Beck, 2018; Pew

679 Resarch Center, 2009) - and are similarly endorsed by liberals and conservatives (e.g., Lindgren, 680 2014).

Although the focal measures employed here are nearly ubiquitous in studies of the 682 relationship between cognitive style and religious belief, they are certainly not without fault. It is 
683 important to note that some of the mismatch between the predictions and results reported here may

684 result from measurement issues. For instance, given our research design we cannot assess the 685 reliability of single item indicators of belief like those used here for belief in God (which also tend

686 to be bimodally distributed). As a consequence, we concede that the models presented here may 687 very well underestimate the magnitude of the relationship between analytical thinking and belief. 688 However, even more reliable multi-item measures such as the often used Supernatural Belief Scale 689 (Jong et al., 2013; used here in Study 2) still exhibit some degree of bimodality (see Figures S1 690 and S2). And thus, new measurement tools may provide further insight. That being said, 691 supernatural beliefs may very well be bimodally distributed in many populations, and thus there 692 may be even more to be gained in the application of novel modelling techniques to potentially 693 capture with greater precision the correlates of religious and supernatural beliefs. Moreover, single 694 item measures of belief do not adequately capture the diversity in the kinds of gods (and other 695 supernatural agents/forces) that people believe in across cultures, and the traits/qualities/capacities 696 afforded to them (Johnson et al., 2019; Lang et al., 2019; Purzycki et al., 2016; Purzycki, Henrich, 697 et al., 2018). In our data, we cannot identify, for example, which God Indian respondents (mostly 698 Hindus) were considering at the time (though we note that belief in God is strongly endorsed by 699 Hindu participants here and in previous research, e.g., White et al., 2019; Baimel, 2019). In so 700 doing, research of this kind may otherwise be missing important pieces of the puzzle of 701 understanding how belief covaries with psychological intuitions. In line with this view, recent 702 evidence from samples of American Hindus suggests that intuitions are more supportive of belief 703 in, for example, personal as opposed to abstract god concepts, even when they are more culturally 704 normative (Baimel, 2019). 
The three-item CRT employed across most of the studies here has more recently been expanded to seven items to increase reliability and relies less on participant's numerical intuitions

707 (Thomson \& Oppenheimer, 2016). And while the data from Stagnaro et al. (2019) as presented in 708 Study 2 provide some evidence of consistency in results between the two versions, future work 709 might benefit from the use of more diverse measures of cognitive style. That being said, we do 710 report some consistency in effect sizes across two distinct measures of cognitive style (the CRT 711 and the self-reported faith in intuition scale). Moreover, the single item measure of political 712 orientation employed in both of our studies could be elaborated into a more reliable and valid 713 measure that also distinguishes between different types or aspects of political orientation (e.g., 714 social vs. economic conservativism). More fine-grained measurements of political orientation may 715 be particularly valuable for future cross-cultural research on this topic that considers more deeply 716 the relationship between religious belief and political orientation (and types of conservatism) in 717 diverse cultural settings.

718 Our results contribute to the growing literature examining the relative contributions of 719 cognition and culture to the form and prevalence of religious beliefs around the world. Willard \& 720 Cingl (2017), for example, provide evidence that the contributions of cultural learning are 721 substantially larger than that of cognitive processes in explaining between-country differences in 722 the prevalence and strength of religious belief. Our results suggest that the contributions of 723 cognition to belief might be greater when the cultural norms to hold certain beliefs are weak (i.e., 724 commitment to religious beliefs in liberals as compared to conservatives). This interpretation fits 725 well with previous work that demonstrates that intuitively-supported cognitive biases are more 726 strongly related to the endorsement of paranormal beliefs than the more culturally-constrained 727 belief in God (Willard \& Norenzayan, 2013). Weighing the relative contributions of cognitive 
728 processes, motivational factors, and cultural learning is essential in broadening our understanding

729 of what supports the world's "theodiversity" (Norenzayan, 2016); and our results also demonstrate

730 that there may be even more to be gained from considering how cognitive processes interact with

731 social and cultural factors in the maintenance of religious beliefs (e.g., see Purzycki \& McNamara,

732 2016). This is an important future direction for the cultural and cognitive sciences of religion.

\section{References}

734 Baimel, A. (2019). Reasoning about the supernatural: A cross-cultural examination of how and 735 when intuitions shape belief. University of British Columbia.

736 Banerjee, K., \& Bloom, P. (2013). Would Tarzan believe in God? Conditions for the emergence

737 of religious belief. Trends in Cognitive Sciences, 17(1), 7-8.

738 https://doi.org/10.1016/j.tics.2012.11.005

739 Beck, J. (2018, January 16). The New Age of Astrology. The Atlantic. https://www.theatlantic.com/health/archive/2018/01/the-new-age-of-astrology/550034/

741 Bürkner, P.-C. (2017). brms: An R Package for Bayesian Multilevel Models Using Stan. Journal of Statistical Software, 80(1). https://doi.org/10.18637/jss.v080.i01

743 Camerer, C. F., Dreber, A., Holzmeister, F., Ho, T.-H., Huber, J., Johannesson, M., Kirchler, M., 744 Nave, G., Nosek, B. A., Pfeiffer, T., Altmejd, A., Buttrick, N., Chan, T., Chen, Y., 745 Forsell, E., Gampa, A., Heikensten, E., Hummer, L., Imai, T., ... Wu, H. (2018).

746 Evaluating the replicability of social science experiments in Nature and Science between 2010 and 2015. Nature Human Behaviour, 2(9), 637. https://doi.org/10.1038/s41562-0180399-z 
749 Chignell, A., \& Pereboom, D. (2020). Natural Theology and Natural Religion. In E. N. Zalta

750 (Ed.), The Stanford Encyclopedia of Philosophy (Fall 2020). Metaphysics Research Lab,

751 Stanford University. https://plato.stanford.edu/archives/fall2020/entries/natural-theology/

752 Daniel Lüdecke. (2018). sjPlot-Data Visualization for Statistics in Social Science. Zenodo.

753 https://doi.org/10.5281/zenodo.1310947

754 De Cruz, H., \& De Smedt, J. (2017). Intuitions and Arguments: Cognitive Foundations of Argumentation in Natural Theology. European Journal for Philosophy of Religion, 9(2), 57. https://doi.org/10.24204/ejpr.v9i2.1934

Deppe, K. D., Gonzalez, F. J., Neiman, J. L., Jacobs, C., Pahlke, J., Smith, K. B., \& Hibbing, J. R. (2015). Reflective liberals and intuitive conservatives: A look at the Cognitive Reflection Test and ideology. Judgment and Decision Making, 10(4), 18.

Frederick, S. (2005). Cognitive reflection and decision making. Journal of Economic Perspectives, 25-42.

762 Gervais, W. M., Elk, M. van, Xygalatas, D., McKay, R., Aveyard, M., Buchtel, E. E. K., DarNimrod, I., Klocová, E. K., Ramsay, J., Riekki, T., Svedholm-Häkkinen, A. M., \& Bulbulia, J. (2017). Analytic atheism: A cross-culturally weak and fickle phenomenon? PsyArXiv. https://doi.org/10.17605/OSF.IO/92R8X

Gervais, W. M., Najle, M., \& Caluori, N. (2019). The Origins of Religious Disbelief: A Dual Inheritance Approach. https://doi.org/10.31234/osf.io/e29rt Pantheon Books. 
772 Järnefelt, E., Canfield, C. F., \& Kelemen, D. (2015). The divided mind of a disbeliever: Intuitive

773 beliefs about nature as purposefully created among different groups of non-religious

774 adults. Cognition, 140, 72-88. https://doi.org/10.1016/j.cognition.2015.02.005

775 Johnson, K. A., Okun, M. A., Cohen, A. B., Sharp, C. A., \& Hook, J. N. (2019). Development

776 and validation of the five-factor LAMBI measure of God representations. Psychology of

777 Religion and Spirituality, 11(4), 339-349. https://doi.org/10.1037/re10000207

778 Jong, J., Bluemke, M., \& Halberstadt, J. (2013). Fear of Death and Supernatural Beliefs:

779

780

Lang, M., Purzycki, B. G., Apicella, C. L., Atkinson, Q. D., Bolyanatz, A., Cohen, E., Handley,

Developing a New Supernatural Belief Scale to Test the Relationship: Developing a new supernatural belief scale. European Journal of Personality, n/a-n/a.

https://doi.org/10.1002/per.1898

Kahan, D. M., Peters, E., Wittlin, M., Slovic, P., Ouellette, L. L., Braman, D., \& Mandel, G. (2012). The polarizing impact of science literacy and numeracy on perceived climate change risks. Nature Climate Change, 2(10), 732-735. https://doi.org/10.1038/nclimate1547

Kahan, D. M., \& Stanovich, K. (2016). Rationality and Belief in Human Evolution (SSRN Scholarly Paper ID 2838668). Social Science Research Network. https://papers.ssrn.com/abstract $=2838668$

Kay, A. C., Gaucher, D., McGregor, I., \& Nash, K. (2010). Religious Belief as Compensatory Control. Personality and Social Psychology Review, 14(1), 37-48. https://doi.org/10.1177/1088868309353750

C., Kundtová Klocová, E., Lesorogol, C., Mathew, S., McNamara, R. A., Moya, C., Placek, C. D., Soler, M., Vardy, T., Weigel, J. L., Willard, A. K., Xygalatas, D., 
Norenzayan, A., \& Henrich, J. (2019). Moralizing gods, impartiality and religious parochialism across 15 societies. Proceedings of the Royal Society B: Biological Sciences, 286(1898), 20190202. https://doi.org/10.1098/rspb.2019.0202

798

799

800

801

802

803

804

805

806

Lanman, J. A., \& Buhrmester, M. D. (2016). Religious actions speak louder than words: Exposure to credibility-enhancing displays predicts theism. Religion, Brain \& Behavior, 1-14. https://doi.org/10.1080/2153599X.2015.1117011

Lindeman, M., Svedholm-Häkkinen, A. M., \& Lipsanen, J. (2015). Ontological confusions but not mentalizing abilities predict religious belief, paranormal belief, and belief in supernatural purpose. Cognition, 134, 63-76. https://doi.org/10.1016/j.cognition.2014.09.008

Lindgren, J. (2014). Who believes that astrology is scientific? Northwestern Public Law Research Paper, 14-10. https://papers.ssrn.com/sol3/papers.cfm?abstract_id=2395697

McElreath, R. (2015). Statistical Rethinking: A Bayesian Course with Examples in R and Stan. Chapman and Hall/CRC.

Nail, P. R., McGregor, I., Drinkwater, A. E., Steele, G. M., \& Thompson, A. W. (2009). Threat causes liberals to think like conservatives. Journal of Experimental Social Psychology, 45(4), 901-907. https://doi.org/10.1016/j.jesp.2009.04.013

Norenzayan, A. (2016). Theodiversity. Annual Review of Psychology, 67(1). https://doi.org/10.1146/annurev-psych-122414-033426

Norenzayan, A., \& Gervais, W. M. (2013). The origins of religious disbelief. Trends in Cognitive Sciences, 17(1), 20-25. https://doi.org/10.1016/j.tics.2012.11.006 
816 Norenzayan, A., Shariff, A. F., Gervais, W. M., Willard, A. K., McNamara, R. A., Slingerland,

817 E., \& Henrich, J. (2016). The cultural evolution of prosocial religions. Behavioral and

818 Brain Sciences, 39, e1 (19 pages). https://doi.org/10.1017/S0140525X14001356

819 Pacini, R., \& Epstein, S. (1999). The relation of rational and experiential information processing 820 styles to personality, basic beliefs, and the ratio-bias phenomenon. Journal of Personality 821 and Social Psychology, 76(6), 972-987. https://doi.org/10.1037/0022-3514.76.6.972

822 Pennycook, G., Cheyne, J. A., Koehler, D. J., \& Fugelsang, J. A. (2016). Is the cognitive reflection test a measure of both reflection and intuition? Behavior Research Methods, 48(1), 341-348. https://doi.org/10.3758/s13428-015-0576-1

Pennycook, G., Cheyne, J. A., Seli, P., Koehler, D. J., \& Fugelsang, J. A. (2012). Analytic cognitive style predicts religious and paranormal belief. Cognition, 123(3), 335-346.

Pennycook, G., Ross, R. M., Koehler, D. J., \& Fugelsang, J. A. (2016). Atheists and Agnostics https://doi.org/10.1016/j.cognition.2012.03.003 Are More Reflective than Religious Believers: Four Empirical Studies and a Meta-

Pew Resarch Center. (2009). Reading the Stars. Pew Research Center. Analysis. PLOS ONE, 11(4), e0153039. https://doi.org/10.1371/journal.pone.0153039

833 Pew Resarch Center. (2020). Is Belief in God Necessary for Good Values? Global Survey on Religion and Morality. https://www.pewresearch.org/global/2020/07/20/the-global-goddivide/

836 Pew Research Center. (2014). Political Polarization in the American Public. 124.

837 Pew Research Center. (2017). The Partisan Divide on Political Values Grows Even Wider. 
838 Purzycki, B. G. (2013). The minds of gods: A comparative study of supernatural agency. Cognition, 129(1), 163-179. https://doi.org/10.1016/j.cognition.2013.06.010

Purzycki, B. G., Apicella, C., Atkinson, Q. D., Cohen, E., McNamara, R. A., Willard, A. K., Xygalatas, D., Norenzayan, A., \& Henrich, J. (2016). Moralistic gods, supernatural punishment and the expansion of human sociality. Nature, 530(7590), 327-330.

Purzycki, B. G., Henrich, J., Apicella, C., Atkinson, Q. D., Baimel, A., Cohen, E., McNamara, R.

Purzycki, B. G., \& McNamara, R. A. (2016). An ecological theory of gods' minds. In Advances in Religion, Cognitive Science, and Expreimental Philosophy. Bloomsbury Publishing.

Purzycki, B. G., Pisor, A. C., Apicella, C., Atkinson, Q., Cohen, E., Henrich, J., McElreath, R., A., Willard, A. K., Xygalatas, D., \& Norenzayan, A. (2018). The evolution of religion and morality: A synthesis of ethnographic and experimental evidence from eight societies. Religion, Brain \& Behavior, 8(2), 101-132. https://doi.org/10.1080/2153599X.2016.1267027

https.//doi.org/10.1080/2153599X.2016.1267027 https://doi.org/10.1038/nature16980 
860 Saribay, S. A., Yilmaz, O., \& Körpe, G. G. (2020). Does intuitive mindset influence belief in God? A registered replication of Shenhav, Rand and Greene (2012). Judgment and Decision Making, 10.

863 Shenhav, A., Rand, D. G., \& Greene, J. D. (2012). Divine intuition: Cognitive style influences belief in God. Journal of Experimental Psychology: General, 141(3), 423-428.

Stagnaro, M. N., Ross, R. M., Pennycook, G., \& Rand, D. G. (2019). Cross-cultural support for a link between analytic thinking and disbelief in God: Evidence from India and the United Kingdom. Judgment and Decision Making, 14, 179-186.

Stan Development Team. (2017). RStan: The R interface to Stan. http://mc-stan.org

870 Thomson, K. S., \& Oppenheimer, D. M. (2016). Investigating an alternate form of the cognitive reflection test. Judgment and Decision Making; Tallahassee, 11(1), 99-113.

872 Vehtari, A., Gelman, A., \& Gabry, J. (2017). Practical Bayesian model evaluation using leaveone-out cross-validation and WAIC. Statistics and Computing, 27(5), 1413-1432. https://doi.org/10.1007/s11222-016-9696-4

White, C. J., Baimel, A., \& Norenzayan, A. (2021). How cultural learning and cognitive biases shape religious beliefs. Current Opinion in Psychology, 40, 34-39. https://doi.org/10.1016/j.copsyc.2020.07.033 Karma Across Cultures. Personality and Social Psychology Bulletin, 0146167218808502. https://doi.org/10.1177/0146167218808502 
881 Willard, A. K., \& Cingl, L. (2017). Testing Theories of Secularization and Religious Belief in 882 the Czech Republic and Slovakia. Evolution and Human Behavior, 0(0).

883 https://doi.org/10.1016/j.evolhumbehav.2017.01.002

884 Willard, A. K., Cingl, L., \& Norenzayan, A. (2020). Cognitive Biases and Religious Belief: A 885 Path Model Replication in the Czech Republic and Slovakia With a Focus on 886 Anthropomorphism. Social Psychological and Personality Science, 11(1), 97-106. https://doi.org/10.1177/1948550619841629

888 Willard, A. K., \& Norenzayan, A. (2013). Cognitive biases explain religious belief, paranormal 889 belief, and belief in life's purpose. Cognition, 129(2), 379-391.

890 https://doi.org/10.1016/j.cognition.2013.07.016 
Table 1. Bayesian model evaluations

\begin{tabular}{llcc}
\hline Belief & Predictor & \multicolumn{2}{c}{$E L P D$ Difference $(S E)$} \\
\cline { 3 - 4 } & & $\begin{array}{c}\text { Dual Process } \\
\text { Model }\end{array}$ & $\begin{array}{c}\text { Expressive Rationality } \\
\text { Model }\end{array}$ \\
\hline God & CRT & $-165.2(16.8)$ & 0 \\
God & Intuition & $-172.6(15.6)$ & 0 \\
Morality & CRT & $-153.5(18.3)$ & 0 \\
Karma & CRT & 0 & $-0.5(.3)$ \\
Karma & Intuition & $-14.4(5.6)$ & 0 \\
Witchcraft & CRT & 0 & $-0.9(.2)$ \\
Witchcraft & Intuition & $-16.7(4.5)$ & 0 \\
\hline
\end{tabular}

Notes: ELPD difference is the difference in expected log predictive densities estimated by the loo package (Vehtari, Gelman, \& Gabry, 2017). Differences smaller than 4 (absolute value) are typically considered to be small and indicative of little to no difference in predictive accuracy. The greater the difference, and smaller the standard error, the larger the difference in predictive performance. "0"s here are indicative of the model with greater predictive performance (e.g., the expressive rationality models in all but two cases where there is no clear indication of any differences). Dual process model estimates are those of models that predicted belief from analytical thinking in each sample; expressive rationality model estimates are those of models that included the additional interaction term between analytical thinking and political orientation in each sample. 
Table 2. Estimated regression coefficients and posterior probabilities

\begin{tabular}{|c|c|c|c|c|c|c|c|c|}
\hline Belief & Predictor & Sample & $b_{A V G}[\mathrm{HDI}]$ & $p(b<0)$ & $b_{L I B}[\mathrm{HDI}]$ & $b_{C O N}[\mathrm{HDI}]$ & $\triangle H D I$ & $p\left(b_{L I B}<b_{C O N}\right)$ \\
\hline God & CRT & Students & $-3.14[-4.23,-2.12]$ & .99 & $-4.22[-5.70,-2.76]$ & $-2.06[-3.12,-1.01]$ & {$[-3.65,-0.73]$} & .99 \\
\hline God & CRT & Americans & $-5.37[-6.53,-4.13]$ & .99 & $-6.03[-7.47,-4.37]$ & $-4.70[-5.78,-3.77]$ & {$[-2.47,-0.23]$} & .98 \\
\hline God & Intuition & Canadians & $-2.84[-3.76,-1.91]$ & .99 & $-4.02[-5.37,-2.75]$ & $-1.65[-2.93,-0.38]$ & {$[-4.25,-0.45]$} & .98 \\
\hline God & Intuition & Indians & $-4.60[-5.87,-3.28]$ & .99 & $-6.33[-8.05,-4.64]$ & $-2.86[-4.64,-0.83]$ & {$[-6.10,-0.88]$} & .98 \\
\hline Karma & CRT & Americans & $-1.78[-3.23,-0.47]$ & .98 & $-1.70[-3.45,0.11]$ & $-1.85[-3.68,-0.05]$ & {$[-2.21,2.51]$} & .45 \\
\hline Karma & Intuition & Canadians & $-5.56[-6.43,-4.63]$ & .99 & $-6.19[-7.47,-5.00]$ & $-4.92[-6.08,-3.69]$ & {$[-2.91,0.37]$} & .90 \\
\hline Karma & Intuition & Americans & $-4.70[-5.68,-3.75]$ & .99 & $-6.39[-7.53,-5.14]$ & $-3.01[-4.46,-1.61]$ & {$[-5.23,-1.59]$} & .99 \\
\hline Karma & Intuition & Indians & $-4.44[-5.15,-3.62]$ & .99 & $-5.14[-6.02,-4.07]$ & $-3.73[-4.81,-2.62]$ & {$[-2.89,0.05]$} & .94 \\
\hline Witchcraft & CRT & Americans & $-2.24[-3.51,-1.02]$ & .99 & $-2.22[-3.87,-0.64]$ & $-2.24[-3.96,-0.65]$ & {$[-2.18,2.18]$} & .48 \\
\hline Witchcraft & Intuition & Americans & $-2.19[-3.24,-1.00]$ & .99 & $-4.61[-6.01,-3.22]$ & $0.23[-1.46,1.92]$ & {$[-7.01,-2.71]$} & .99 \\
\hline Witchcraft & Intuition & Indians & $-0.82[-2.00,0.35]$ & .87 & $-2.32[-3.81,-0.60]$ & $0.68[-1.04,2.27]$ & {$[-5.39,-0.60]$} & .98 \\
\hline Morality & CRT & Students & $-1.82[-2.57,-1.04]$ & .99 & $-2.78[-3.81,-1.70]$ & $-0.85[-1.97,0.17]$ & {$[-3.48,-0.40]$} & .99 \\
\hline Morality & CRT & Americans & $-2.74[-3.43,-2.12]$ & .99 & $-3.58[-4.54,-2.74]$ & $-1.90[-2.77,-1.06]$ & {$[-2.87,-0.50]$} & .99 \\
\hline
\end{tabular}

Notes: Regression parameters ' $b$ 's indicate estimated difference in belief on the 100-point response scale $($ Min $=0$; Max $=100)$ for each additional correct analytical answer on the CRT or a one standard deviation increase in analytical thinking as measured by the Faith in Intuition scale (which was reverse coded so direction of parameters are comparable to those of the CRT). Intervals around these point estimates (HDI) represent the $95 \%$ most probable parameter values. Regression parameters are presented for the effects of CRT/Intuition at mean political orientation $\left(b_{A V G}[\mathrm{HDI}]\right)$, in more liberal individuals $\left(b_{L I B}\right)$ and more conservative individuals $\left(b_{C O N}\right)$, as they are plotted in Figure 1. The difference between more liberal and more conservative individuals is presented in the second to last column $(\triangle H D I)$. The posterior probability that the average effect of analytical thinking is negative is presented in the ' $p(b<0)$ ' column. The posterior probability that the effect was stronger in more liberal participants than conservatives is presented in the last column $\left(p\left(b_{L I B}<b_{C O N}\right)\right.$. Students were recruited from the human subject pool at the University of British Columbia, Canada. 
1 Table 3. Estimated contributions of analytical thinking to belief by sample and political 2 orientation

\begin{tabular}{|c|c|c|c|c|}
\hline Source & Outcome & $\begin{array}{c}\text { Political } \\
\text { Orientation }\end{array}$ & $b[95 \% \mathrm{HDI}]$ & $p(b+\mathrm{LIB}<b+\mathrm{CON})$ \\
\hline \multirow{4}{*}{$\begin{array}{l}\text { Gervais et } \\
\text { al. }(2017)\end{array}$} & \multirow{4}{*}{$\begin{array}{l}\text { Belief in } \\
\text { God }\end{array}$} & + Liberal & $-2.41[-5.31,0.97]$ & \multirow{4}{*}{.79} \\
\hline & & Liberal & $-1.65[-3.32,0.11]$ & \\
\hline & & Conservative & $-0.89[-2.81,1.02]$ & \\
\hline & & + Conservative & $-0.13[-3.49,3.26]$ & \\
\hline \multirow{8}{*}{$\begin{array}{l}\text { Stagnaro et } \\
\text { al. (2017) }\end{array}$} & \multirow{4}{*}{$\begin{array}{l}\text { Belief in } \\
\text { God }\end{array}$} & + Liberal & $-4.21[-5.90,-2.50]$ & \multirow{4}{*}{.99} \\
\hline & & Liberal & $-3.01[-4.28,-1.77]$ & \\
\hline & & Conservative & $-0.61[-2.17,0.86]$ & \\
\hline & & + Conservative & $0.59[-1.53,2.56]$ & \\
\hline & \multirow{4}{*}{$\begin{array}{l}\text { Supernatural } \\
\text { belief }\end{array}$} & + Liberal & $-5.19[-6.64,-3.61]$ & \multirow{4}{*}{.99} \\
\hline & & Liberal & $-3.93[-5.02,-2.82]$ & \\
\hline & & Conservative & $-1.42[-2.72,-0.02]$ & \\
\hline & & +Conservative & $-0.16[-1.99,1.73]$ & \\
\hline
\end{tabular}

4 Notes. Estimates are differences in belief (0-100) for each additional correct response on the 5 CRT.The last column presents the posterior probability that the estimated association in the most 6 liberal ("+LIB") is more negative than in the most conservative ("+CON"). 
Figure 1. Posterior distribution of the estimated associations between analytical thinking and varied beliefs by sample and political orientation.

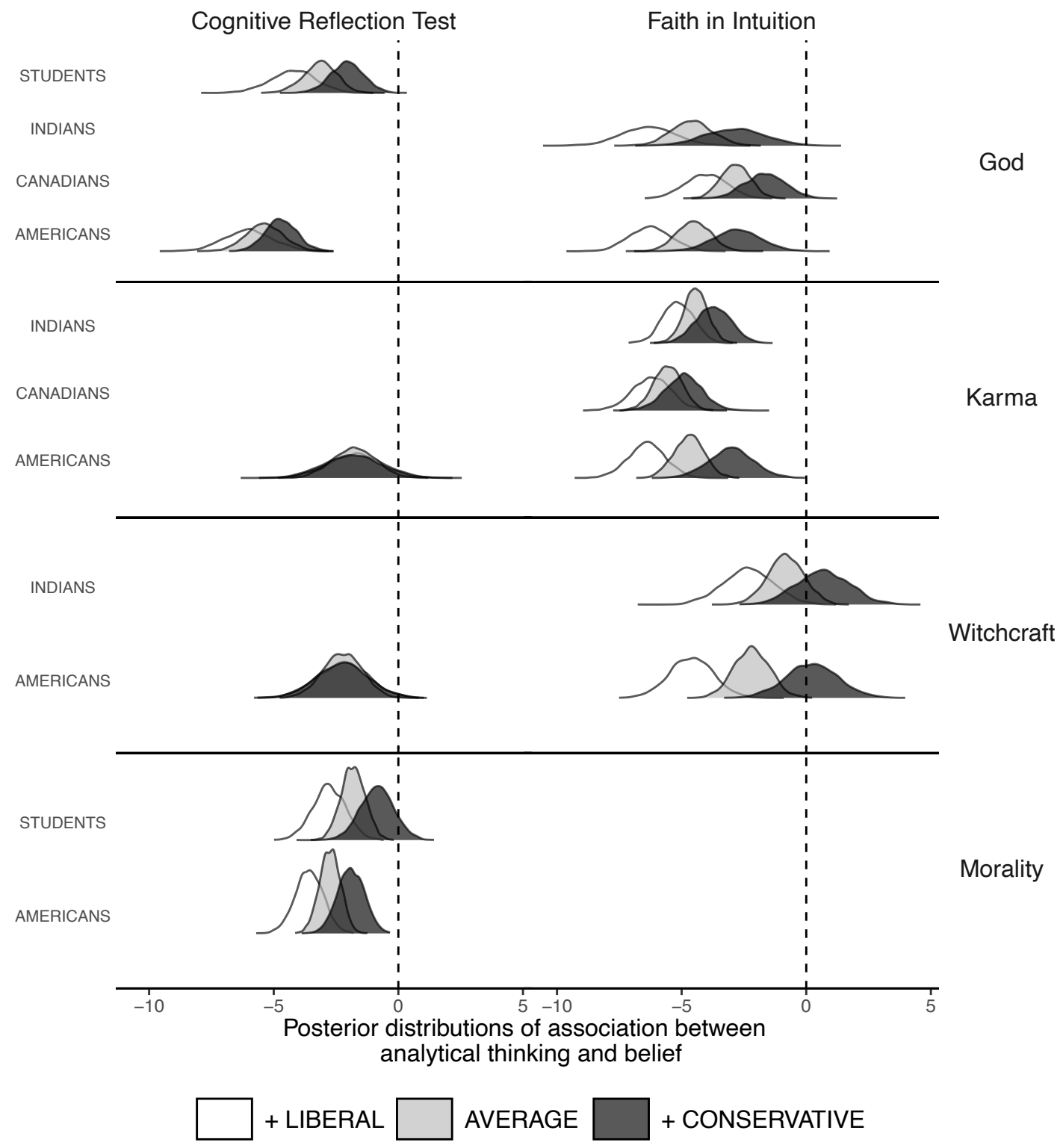

Notes: Students were recruited from the human subject pool at the University of British Columbia, Canada. X-axis values are of estimated change in belief with each additional correct answer on the CRT and one standard deviation increase in analytical thinking as measured by the faith in intuition scale which has been reverse scored so the direction of predictions is matched to those of the CRT. With the bulk of the posterior distributions in all instances being to the left of the dashed lines (i.e., below zero), these data largely support the dual process model. The expressive rationality model predicts that the posterior distributions in more conservative individuals for identity-relevant beliefs (belief in God/belief that religion is necessary for morality) would fall to the right of the dashed line (i.e., above zero) - a pattern of results that is not observed here. For more information about these estimates see Table 2. 
Figure 2. Posterior predictions of belief from analytical thinking and political orientation
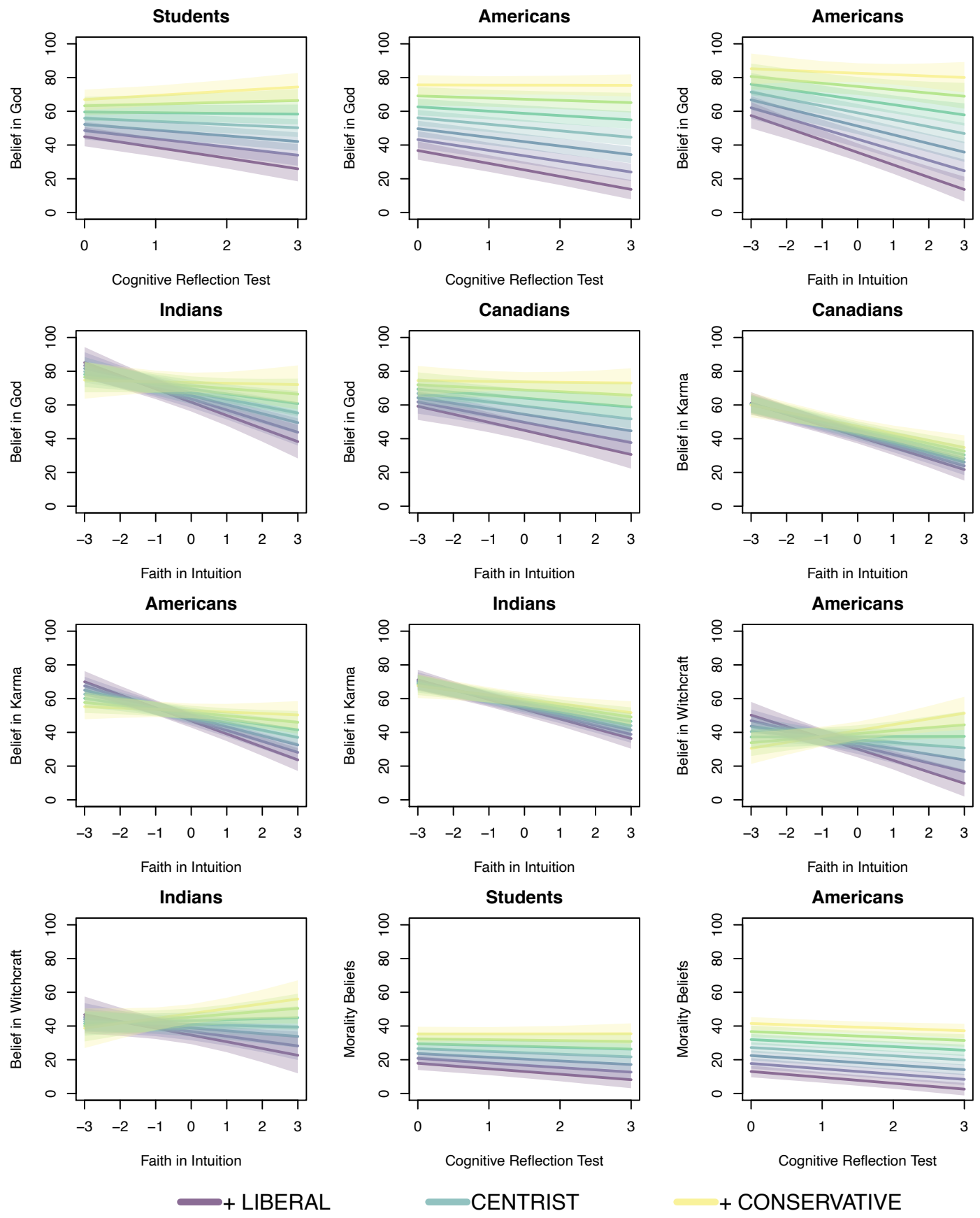

Notes: Predictions estimated from 8000 draws from the posterior distributions of each parameter. Purple lines indicating predictions for the most liberal, yellow lines indicating predictions for the most conservative. Shaded regions are $95 \%$ prediction intervals. Students were recruited from the human subject pool at the University of British Columbia, Canada. 
1 Figure 3. Posterior distributions of the estimated regression coefficients of analytical thinking 2 predicting belief by political orientation

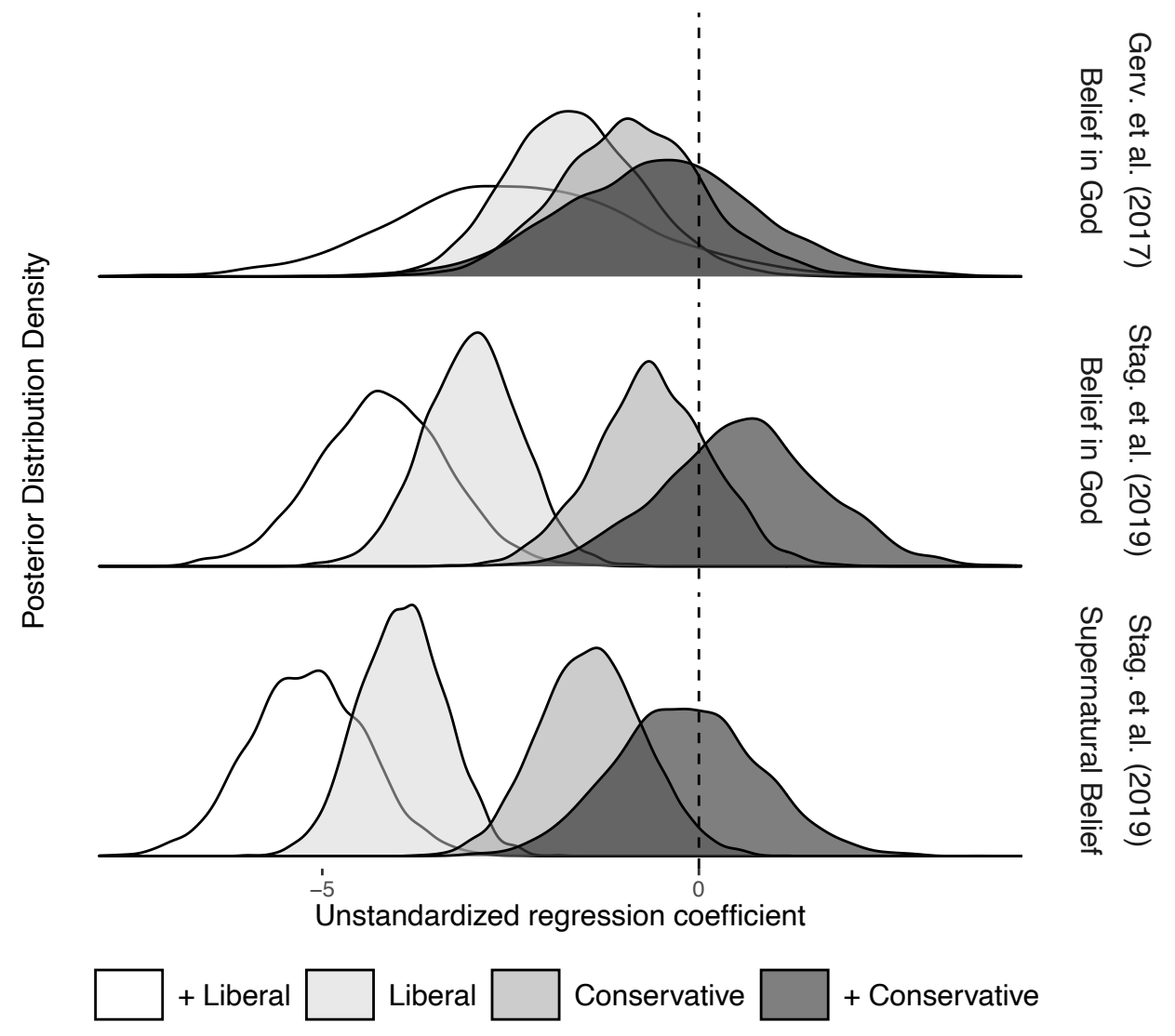


5 How is analytical thinking related to religious belief? A test of three theoretical models 6

Supplemental Materials 


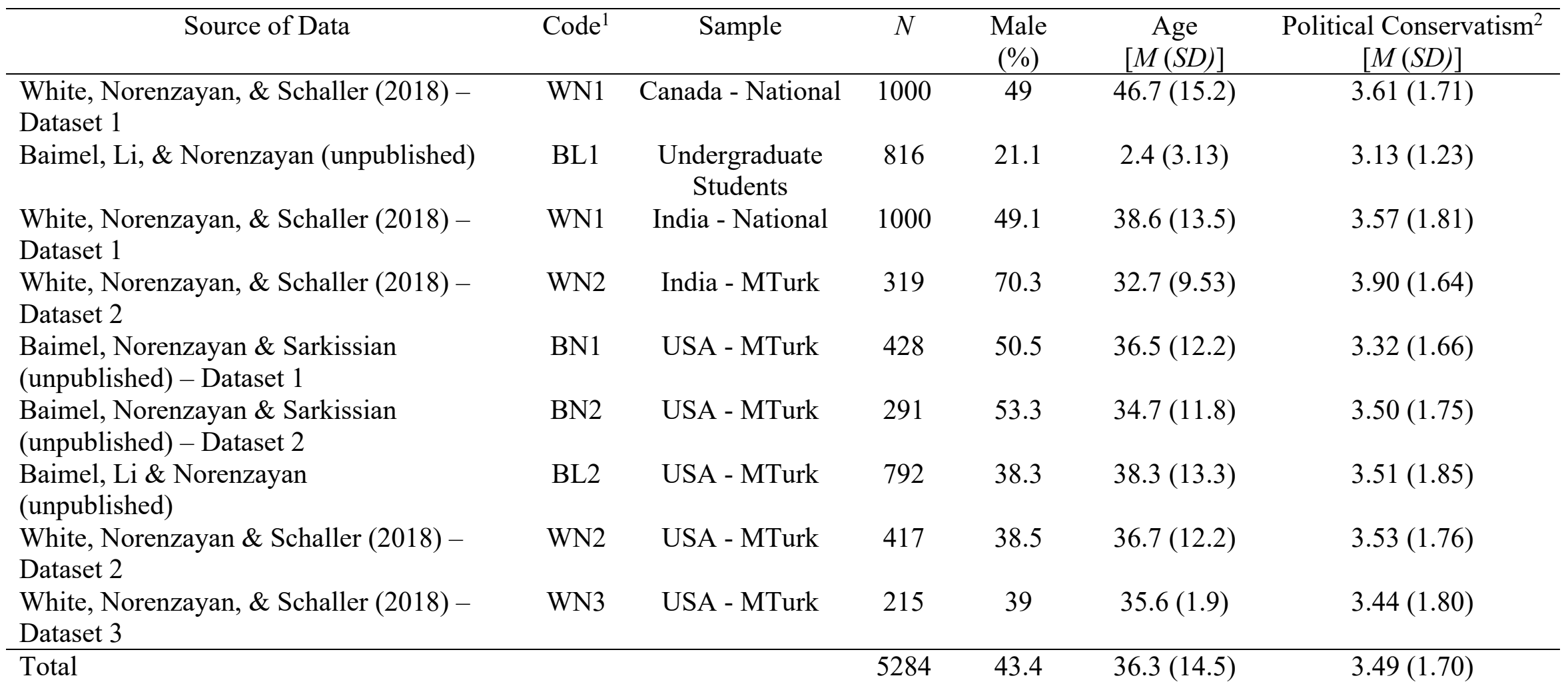

9 Notes: ${ }^{1}$ Code is recorded in the SOURCE variable in the dataset associated with Study $1 .{ }^{2}$ Political orientation was assessed on a $1=$

10 very liberal to $7=$ very conservative response scale. Students were recruited from the human subject pool at the University of British

11 Columbia, Canada. 
12 Table S2 Included measures in each dataset

\begin{tabular}{lccccccc}
\hline Source & Sample & Belief in God & CRT & REI & KARMA & WITCH & MORAL \\
\hline WN1 & Canadians & $1-7$ Scale (1 item) & & 5 pt & $\checkmark$ & & \\
BL1 & Students & $1-7$ Scale (1 item) & $\checkmark$ & & & & $7 \mathrm{pt}$ \\
WN1 & Indians & $1-7$ Scale (1 item) & & $5 \mathrm{pt}$ & $\checkmark$ & & \\
WN2 & Indians & $1-5$ Scale (3 items) & & $7 \mathrm{pt}$ & $\checkmark$ & $\checkmark$ & \\
BN1 & Americans & $1-7$ Scale (1 item) & $\checkmark$ & $7 \mathrm{pt}$ & & & $6 \mathrm{pt}$ \\
BN2 & Americans & $1-7$ Scale (1 item) & $\checkmark$ & $7 \mathrm{pt}$ & & & $6 \mathrm{pt}$ \\
BL2 & Americans & $1-7$ Scale (1 item) & $\checkmark$ & & & & $7 \mathrm{pt}$ \\
WN2 & Americans & $1-5$ Scale (3 items) & & $7 \mathrm{pt}$ & $\checkmark$ & $\checkmark$ & \\
WN3 & Americans & $1-5$ Scale (3 items) & $\checkmark$ & $7 \mathrm{pt}$ & $\checkmark$ & $\checkmark$ & \\
\hline
\end{tabular}

13 Notes: CRT $=$ Cognitive Reflections Test; REI $=$ Faith in Intuition subscale from the Rational

14 Experiential Inventory; KARMA $=$ Belief in Karma Scale; WITCH = Belief in Witchcraft;

15 MORAL $=$ Belief that religion is necessary for morality. Variables coded on different response

16 scales are identified in this table (5-, 6-, or 7-point scales). For comparison and analyses (to handle

17 these differences), all responses were rescaled to a 100 point response scale $(0=$ Minimum belief;

$18100=$ maximum belief). REI-Faith in Intuition subscales were rescaled to a 0 to 1 scale, and then

19 reverse coded such that higher scores indicated less faith in intuition (greater analytical thinking;

20 to ease comparison between this scale and the Cognitive Reflection Test). Students were recruited

21 from the human subject pool at the University of British Columbia, Canada. 
29 Table S3 Means (standard deviations) of focal measures by sample (rescaled)

\begin{tabular}{|c|c|c|c|c|c|c|c|}
\hline Source & Sample & $\begin{array}{c}\text { Belief } \\
(0-100)\end{array}$ & $\begin{array}{l}\text { CRT } \\
(0-3)\end{array}$ & $\begin{array}{l}\text { INT } \\
(0-1)\end{array}$ & $\begin{array}{c}\text { KARMA } \\
(0-100)\end{array}$ & $\begin{array}{l}\text { WITCH } \\
(0-100)\end{array}$ & $\begin{array}{l}\text { MORAL } \\
(0-100)\end{array}$ \\
\hline WN1 & Canada & $\begin{array}{c}58.00 \\
(37.80)\end{array}$ & --- & $\begin{array}{l}.36 \\
(.16)\end{array}$ & $\begin{array}{c}42.80 \\
(20.50)\end{array}$ & --- & --- \\
\hline BL1 & Students & $\begin{array}{l}40.20 \\
(38.0)\end{array}$ & $\begin{array}{c}1.53 \\
(1.21)\end{array}$ & --- & --- & --- & $\begin{array}{c}15.20 \\
(16.40)\end{array}$ \\
\hline WN1 & India & $\begin{array}{c}85.00 \\
(25.20)\end{array}$ & --- & $\begin{array}{c}.34 \\
(.14)\end{array}$ & $\begin{array}{l}67.30 \\
(18.10)\end{array}$ & --- & --- \\
\hline WN2 & India & $\begin{array}{l}74.30 \\
(21.30)\end{array}$ & --- & $\begin{array}{l}.37 \\
(.12)\end{array}$ & $\begin{array}{l}65.80 \\
(20.70)\end{array}$ & $\begin{array}{l}55.60 \\
(19.70)\end{array}$ & --- \\
\hline BN1 & USA & $\begin{array}{c}41.00 \\
(39.70)\end{array}$ & $\begin{array}{c}1.51 \\
(1.25)\end{array}$ & $\begin{array}{c}.45 \\
(.17)\end{array}$ & --- & --- & $\begin{array}{c}23.40 \\
(25.60)\end{array}$ \\
\hline $\mathrm{BN} 2$ & USA & $\begin{array}{c}39.70 \\
(40.90)\end{array}$ & $\begin{array}{c}1.53 \\
(1.19)\end{array}$ & $\begin{array}{c}.45 \\
(.17)\end{array}$ & --- & --- & $\begin{array}{c}23.70 \\
(28.60)\end{array}$ \\
\hline BL2 & USA & $\begin{array}{c}50.00 \\
(42.10)\end{array}$ & $\begin{array}{c}1.30 \\
(1.23)\end{array}$ & --- & --- & --- & $\begin{array}{c}21.50 \\
(25.20)\end{array}$ \\
\hline WN2 & USA & $\begin{array}{c}64.60 \\
(33.30)\end{array}$ & --- & $\begin{array}{c}.31 \\
(.17)\end{array}$ & $\begin{array}{c}43.40 \\
(24.70)\end{array}$ & $\begin{array}{l}33.00 \\
(24.40)\end{array}$ & --- \\
\hline WN3 & USA & $\begin{array}{c}60.70 \\
(35.70)\end{array}$ & $\begin{array}{c}1.47 \\
(1.20)\end{array}$ & $\begin{array}{c}.34 \\
(.20)\end{array}$ & $\begin{array}{c}42.70 \\
(28.40)\end{array}$ & $\begin{array}{l}28.10 \\
(22.50)\end{array}$ & --- \\
\hline
\end{tabular}

31 Notes: CRT $=$ Cognitive Reflections Test; INT = Reverse coded faith in Intuition subscale from

32 the Rational Experiential Inventory. KARMA $=$ Belief in Karma scale. WITCH $=$ Belief in

33 witchcraft scale; MORAL = Belief that religion is necessary for morality. Students were recruited

34 from the human subject pool at the University of British Columbia, Canada. 
36 Table S4. Correlations [95\% confidence intervals] of focal variables by sample

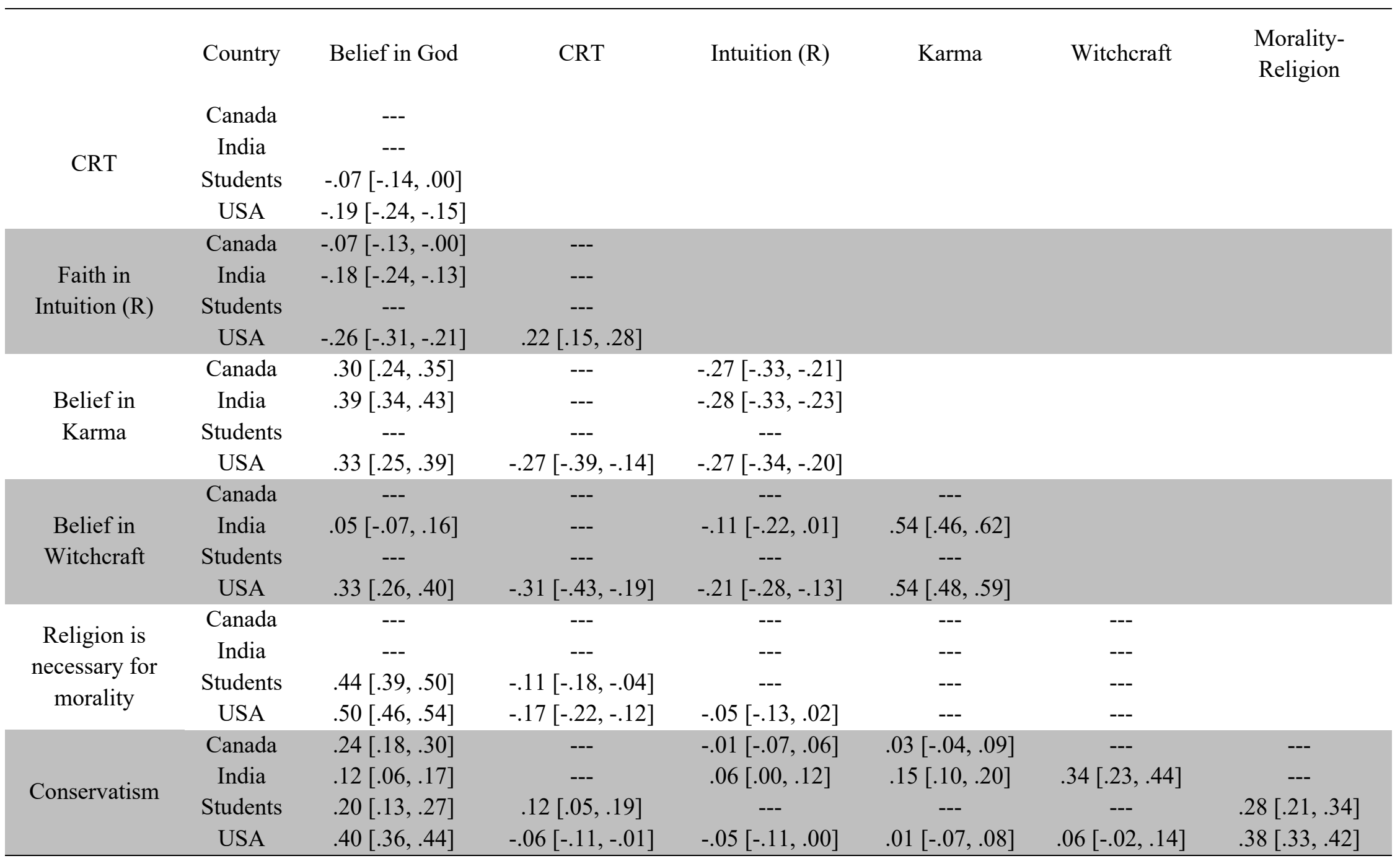

37 Notes: Students were recruited from the human subject pool at the University of British Columbia, Canada. 
38 Table S5. Factor loadings of items measuring the belief that religion is necessary for morality

\begin{tabular}{|c|c|}
\hline Items & Loading \\
\hline 1. An individual who does not believe in God cannot lead a moral life & .95 \\
\hline 2. An individual who does not attend religious services cannot lead a moral life & .93 \\
\hline 3. An individual who does not practice any religion cannot lead a moral life & .97 \\
\hline 4. Religious texts should be understood literally & .72 \\
\hline 5. Generally speaking, people need religion to be morally good. & .86 \\
\hline
\end{tabular}


41 Table S6. Regression summaries - Belief in God \& CRT

42

\begin{tabular}{|c|c|c|c|c|}
\hline \multirow{2}{*}{$\begin{array}{l}\text { Belief in God } \\
\text { Predictors } \\
\end{array}$} & \multicolumn{2}{|c|}{ Dual Process Model } & \multicolumn{2}{|c|}{$\begin{array}{c}\text { Expressive } \\
\text { Rationality Model }\end{array}$} \\
\hline & Estimates & $C I(95 \%)$ & Estimates & $C I(95 \%)$ \\
\hline Intercept & 52.11 & $46.23-58.29$ & 42.79 & $37.03-48.73$ \\
\hline CRT in Students & -2.45 & $-3.71--1.18$ & -3.12 & $-4.50--1.91$ \\
\hline $\begin{array}{l}\text { Difference in belief in Americans } \\
\text { compared to Students }\end{array}$ & 0.26 & $-1.67-2.24$ & 0.16 & $-1.72-2.13$ \\
\hline $\begin{array}{l}\text { Change in the contributions of CRT in } \\
\text { Americans compared to Students }\end{array}$ & -2.30 & $-3.76--0.90$ & -2.24 & $-3.68--0.79$ \\
\hline $\begin{array}{l}\text { Political conservatism in Students } \\
\text { (standardized) }\end{array}$ & & & 3.91 & $2.53-5.31$ \\
\hline $\begin{array}{l}\text { Change in the contributions of CRT with a } \\
\text { 1SD increase in conservatism in Students }\end{array}$ & & & 1.08 & $0.21-1.96$ \\
\hline $\begin{array}{l}\text { Change in the contributions of } \\
\text { conservatism in Americans compared to } \\
\text { Students }\end{array}$ & & & 3.38 & $1.95-4.74$ \\
\hline $\begin{array}{l}\text { Change in the contributions of CRT with a } \\
\text { 1SD increase in conservatism in } \\
\text { Americans }\end{array}$ & & & -0.42 & $-1.37-0.49$ \\
\hline Observations & 2469 & & 2469 & \\
\hline
\end{tabular}

44 Notes: Models included a random intercept for dataset. Reference category for Sample $=$ 45 undergraduate students at a Canadian university. Key estimates for tests of each model are 46 bolded. 
Table S7. Regression summaries - Belief in God \& Faith in Intuition (R)

50

\begin{tabular}{|c|c|c|c|c|}
\hline \multirow{2}{*}{$\begin{array}{l}\text { Belief in God } \\
\text { Predictors } \\
\end{array}$} & \multicolumn{2}{|c|}{ Dual Process Model } & \multicolumn{2}{|c|}{$\begin{array}{c}\text { Expressive } \\
\text { Rationality Model }\end{array}$} \\
\hline & Estimates & CI $(95 \%)$ & Estimates & $C I(95 \%)$ \\
\hline Intercept & 56.32 & $49.25-63.07$ & 56.36 & $49.36-63.02$ \\
\hline $\begin{array}{l}\text { Faith in Intuition (Reverse scored, } \\
\text { standardized) }\end{array}$ & -2.92 & $-4.14--1.76$ & -2.84 & $-3.97--1.69$ \\
\hline $\begin{array}{l}\text { Difference in belief in Indians compared to } \\
\text { Canadians }\end{array}$ & 8.32 & $6.77-9.87$ & 8.73 & $7.18-10.32$ \\
\hline $\begin{array}{l}\text { Difference in belief in Americans } \\
\text { compared to Canadians }\end{array}$ & -0.67 & $-2.49-1.24$ & -0.44 & $-2.28-1.41$ \\
\hline $\begin{array}{l}\text { Change in the contributions of intuition in } \\
\text { Indians compared to Canadians }\end{array}$ & -1.66 & $-3.19--0.10$ & -1.77 & $-3.30--0.21$ \\
\hline $\begin{array}{l}\text { Change in the contributions of intuition in } \\
\text { Americans compared to Canadians }\end{array}$ & -1.98 & $-3.42--0.55$ & -1.68 & $-3.13--0.26$ \\
\hline $\begin{array}{l}\text { Political conservatism in Canadians } \\
\text { (standardized) }\end{array}$ & & & 6.18 & $5.05-7.33$ \\
\hline $\begin{array}{l}\text { Change in the contributions of intuition } \\
\text { with a } 1 \text { SD increase in conservatism in } \\
\text { Canadians }\end{array}$ & & & 1.20 & $0.05-2.29$ \\
\hline $\begin{array}{l}\text { Change in the contributions of } \\
\text { conservatism in Indians compared to } \\
\text { Canadians }\end{array}$ & & & -1.38 & $-2.83-0.10$ \\
\hline $\begin{array}{l}\text { Change in the contributions of } \\
\text { conservatism in Americans compared to } \\
\text { Canadians }\end{array}$ & & & 4.90 & $3.45-6.31$ \\
\hline $\begin{array}{l}\text { Change in the contributions of intuition } \\
\text { with a } 1 \mathrm{SD} \text { increase in conservatism in } \\
\text { Indians }\end{array}$ & & & 0.54 & $-0.98-2.10$ \\
\hline $\begin{array}{l}\text { Change in the contributions of intuition } \\
\text { with a } 1 \mathrm{SD} \text { increase in conservatism in } \\
\text { Americans }\end{array}$ & & & 0.55 & $-0.82-1.90$ \\
\hline Observations & 3560 & & 3560 & \\
\hline
\end{tabular}

52 Notes: Models included a random intercept for sample. Reference group for Sample =

53 Canadians. Key estimates for tests of each model are bolded. 
55 Table S8. Regression summaries - Belief that religion is necessary for morality \& CRT

56

\begin{tabular}{|c|c|c|c|c|}
\hline \multirow{2}{*}{$\begin{array}{l}\text { Religion \& Morality } \\
\text { Predictors }\end{array}$} & \multicolumn{2}{|c|}{$\begin{array}{l}\text { Dual Process } \\
\text { Model }\end{array}$} & \multicolumn{2}{|c|}{$\begin{array}{c}\text { Expressive } \\
\text { Rationality Model }\end{array}$} \\
\hline & Estimates & $C I(95 \%)$ & Estimates & $C I(95 \%)$ \\
\hline Intercept & 24.13 & $20.25-28.37$ & 23.70 & $20.11-27.92$ \\
\hline CRT in Students & -1.73 & $-2.74--0.73$ & -1.82 & $-2.75--0.89$ \\
\hline $\begin{array}{l}\text { Difference in belief in Americans } \\
\text { compared to Students }\end{array}$ & 0.62 & $-1.28-2.55$ & 0.67 & $-1.33-2.62$ \\
\hline $\begin{array}{l}\text { Change in the contributions of CRT in } \\
\text { Americans compared to Students }\end{array}$ & -1.26 & $-2.41--0.05$ & -0.92 & $-2.09-0.20$ \\
\hline $\begin{array}{l}\text { Political conservatism in Students } \\
\text { (standardized) }\end{array}$ & & & 3.89 & $2.57-5.23$ \\
\hline $\begin{array}{l}\text { Change in the contributions of CRT with a } \\
1 \mathrm{SD} \text { increase in conservatism in Students }\end{array}$ & & & 0.96 & $0.09-1.88$ \\
\hline $\begin{array}{l}\text { Change in the contributions of } \\
\text { conservatism in Americans compared to } \\
\text { Students }\end{array}$ & & & 2.92 & $1.53-4.41$ \\
\hline $\begin{array}{l}\text { Change in the contributions of CRT with a } \\
1 \mathrm{SD} \text { increase in conservatism in } \\
\text { Americans }\end{array}$ & & & -0.12 & $-1.14-0.85$ \\
\hline Observations & 2263 & & 2263 & \\
\hline
\end{tabular}

58 Notes: Model included a random intercept for sample. Reference category $=$ undergraduate

59 students at a Canadian university. Key estimates for the test of the model are bolded.

60

61 
62 Table S9. Regression summaries - Belief in Karma \& CRT

63

\begin{tabular}{|c|c|c|c|c|}
\hline Karma & & $\begin{array}{l}\text { ll Process } \\
\text { Model }\end{array}$ & $\begin{array}{r}\mathbf{E x}] \\
\text { Ration }\end{array}$ & $\begin{array}{l}\text { pressive } \\
\text { ality Model }\end{array}$ \\
\hline Predictors & Estimates & CI (95\%) & Estimates & CI (95\%) \\
\hline Intercept & 45.61 & $41.06-49.85$ & 45.46 & $40.99-50.02$ \\
\hline CRT in Americans & -1.83 & $-3.47--0.06$ & -1.78 & $-3.43--0.11$ \\
\hline $\begin{array}{l}\text { Political conservatism in Americans } \\
\text { (standardized) }\end{array}$ & & & -0.37 & $-2.21-1.43$ \\
\hline $\begin{array}{l}\text { Change in the contributions of CRT with a } \\
\text { 1SD increase in conservatism in } \\
\text { Americans }\end{array}$ & & & -0.08 & $-1.49-1.30$ \\
\hline Observations & 208 & & 208 & \\
\hline
\end{tabular}


67 Table S10. Regression summaries - Belief in karma \& Faith in Intuition (R)

68

\begin{tabular}{|c|c|c|c|c|}
\hline \multirow{2}{*}{$\begin{array}{r}\text { Karma } \\
\text { Predictors } \\
\end{array}$} & \multicolumn{2}{|c|}{$\begin{array}{l}\text { Dual Process } \\
\text { Model }\end{array}$} & \multicolumn{2}{|c|}{$\begin{array}{l}\text { Expressive } \\
\text { Rationality Model }\end{array}$} \\
\hline & Estimates & CI (95\%) & Estimates & CI $(95 \%)$ \\
\hline Intercept & 56.23 & $51.37-61.04$ & 56.02 & $50.95-60.60$ \\
\hline $\begin{array}{l}\text { Faith in Intuition (Reverse scored, } \\
\text { standardized) }\end{array}$ & -4.45 & $-5.40--3.53$ & -4.44 & $-5.40--3.50$ \\
\hline $\begin{array}{l}\text { Difference in belief in Canadians compared } \\
\text { to Indians }\end{array}$ & -12.26 & $\begin{array}{l}-13.67-- \\
10.84\end{array}$ & -12.30 & $\begin{array}{l}-13.71-- \\
10.91\end{array}$ \\
\hline $\begin{array}{l}\text { Difference in belief in Americans compared } \\
\text { to Indians }\end{array}$ & -6.87 & $-8.52--5.19$ & -6.80 & $-8.56--5.12$ \\
\hline $\begin{array}{l}\text { Change in the contributions of intuition in } \\
\text { Canadians compared to Indians }\end{array}$ & -1.11 & $-2.41-0.16$ & -1.11 & $-2.38-0.14$ \\
\hline $\begin{array}{l}\text { Change in the contributions of intuition in } \\
\text { Americans compared to Indians }\end{array}$ & -0.44 & $-1.76-0.84$ & -0.26 & $-1.57-1.02$ \\
\hline $\begin{array}{l}\text { Political conservatism in Indians } \\
\text { (standardized) }\end{array}$ & & & 2.02 & $1.15-2.90$ \\
\hline $\begin{array}{l}\text { Change in the contributions of intuition with } \\
\text { a } 1 \text { SD increase in conservatism in Indians }\end{array}$ & & & 0.71 & $-0.16-1.58$ \\
\hline $\begin{array}{l}\text { Change in the contributions of conservatism } \\
\text { in Canadians compared to Indians }\end{array}$ & & & -1.07 & $-2.29-0.23$ \\
\hline $\begin{array}{l}\text { Change in the contributions of conservatism } \\
\text { in Canadians compared to Indians }\end{array}$ & & & -0.87 & $-2.25-0.53$ \\
\hline $\begin{array}{l}\text { Change in the contributions of intuition with } \\
\text { a } 1 \mathrm{SD} \text { increase in conservatism in Canadians }\end{array}$ & & & -0.07 & $-1.22-1.14$ \\
\hline $\begin{array}{l}\text { Change in the contributions of intuition with } \\
\text { a } 1 \text { SD increase in conservatism in } \\
\text { Americans }\end{array}$ & & & 0.99 & $-0.25-2.22$ \\
\hline Observations & 2873 & & 2873 & \\
\hline
\end{tabular}

69

70 Notes: Reference group for sample = Indians. Key estimates are bolded. 
71 Table S11. Regression summaries - Belief in witchcraft \& Faith in Intuition (R)

72

\begin{tabular}{|c|c|c|c|c|}
\hline \multirow{2}{*}{$\begin{array}{l}\text { Witchcraft } \\
\text { Predictors } \\
\end{array}$} & \multicolumn{2}{|c|}{$\begin{array}{l}\text { Dual Process } \\
\text { Model }\end{array}$} & \multicolumn{2}{|c|}{$\begin{array}{c}\text { Expressive } \\
\text { Rationality Model }\end{array}$} \\
\hline & Estimates & CI (95\%) & Estimates & CI $(95 \%)$ \\
\hline Intercept & 31.45 & $27.84-35.07$ & 31.58 & $27.84-35.24$ \\
\hline CRT in Americans & -2.23 & $-3.81--0.69$ & -2.24 & $-3.79--0.73$ \\
\hline $\begin{array}{l}\text { Political conservatism in Americans } \\
\text { (standardized) }\end{array}$ & & & 0.15 & $-1.63-1.85$ \\
\hline $\begin{array}{l}\text { Change in the contributions of CRT with a } \\
\text { 1SD increase in conservatism in } \\
\text { Americans }\end{array}$ & & & -0.03 & $-1.28-1.27$ \\
\hline Observations & 208 & & 208 & \\
\hline
\end{tabular}


74 Table S12. Regression summaries - Belief in witchcraft \& Faith in Intuition (R)

75

\begin{tabular}{|c|c|c|c|c|}
\hline \multirow{2}{*}{$\begin{array}{l}\text { Witchcraft } \\
\text { Predictors } \\
\end{array}$} & \multicolumn{2}{|c|}{$\begin{array}{l}\text { Dual Process } \\
\text { Model }\end{array}$} & \multicolumn{2}{|c|}{$\begin{array}{c}\text { Expressive } \\
\text { Rationality Model }\end{array}$} \\
\hline & Estimates & CI (95\%) & Estimates & CI (95\%) \\
\hline Intercept & 40.13 & $33.87-46.33$ & 40.40 & $33.84-46.26$ \\
\hline $\begin{array}{l}\text { Faith in Intuition (Reverse scored, } \\
\text { standardized) }\end{array}$ & -0.94 & $-2.36-0.52$ & -0.83 & $-2.26-0.58$ \\
\hline $\begin{array}{l}\text { Difference in belief in Americans compared to } \\
\text { Indians }\end{array}$ & -5.51 & $-7.19--3.65$ & -5.45 & $-7.20--3.76$ \\
\hline $\begin{array}{l}\text { Change in the contributions of intuition in } \\
\text { Americans compared to Indians }\end{array}$ & -1.58 & $-3.07--0.07$ & -1.37 & $-2.85-0.12$ \\
\hline $\begin{array}{l}\text { Political conservatism in Indians } \\
\text { (standardized) }\end{array}$ & & & 2.66 & $1.29-4.19$ \\
\hline $\begin{array}{l}\text { Change in the contributions of intuition with a } \\
\text { 1SD increase in conservatism in Indians }\end{array}$ & & & 1.49 & $0.09-2.90$ \\
\hline $\begin{array}{l}\text { Change in the contributions of conservatism } \\
\text { in Americans compared to Indians }\end{array}$ & & & -0.37 & $-1.90-1.21$ \\
\hline $\begin{array}{l}\text { Change in the contributions of intuition with a } \\
\text { 1SD increase in conservatism in Americans }\end{array}$ & & & 0.92 & $-0.54-2.38$ \\
\hline Observations & 899 & & 899 & \\
\hline
\end{tabular}


78 Table S13. Model summaries from Study 2

\begin{tabular}{|c|c|c|c|c|c|c|}
\hline \multirow[b]{3}{*}{ Predictors } & \multirow{2}{*}{\multicolumn{2}{|c|}{$\begin{array}{c}\text { Model 1: } \\
\text { Belief in God } \\
\text { Gervais et al (2017) }\end{array}$}} & \multicolumn{2}{|c|}{$\begin{array}{l}\text { Model 2: } \\
\text { Belief in God }\end{array}$} & \multicolumn{2}{|c|}{$\begin{array}{c}\text { Model 3: } \\
\text { Supernatural Belief }\end{array}$} \\
\hline & & & \multicolumn{4}{|c|}{ Stagnaro et al (2019) } \\
\hline & Estimates & $H D I(95 \%)$ & Estimates & $H D I(95 \%)$ & Estimates & $H D I(95 \%)$ \\
\hline Intercept & 62.39 & $51.56-72.05$ & 41.54 & $36.71-47.40$ & 57.81 & $53.36-62.84$ \\
\hline $\mathrm{CRT}^{1}$ & -1.31 & $-2.81-0.24$ & -1.82 & $-2.93--0.54$ & -2.67 & $-3.68--1.60$ \\
\hline Conservatism $^{2}$ & 0.34 & $-1.04-1.75$ & 0.25 & $-1.56-2.04$ & -.14 & $-1.99-1.68$ \\
\hline CRT $*$ Conservatism & 0.38 & $-0.64-1.29$ & 1.20 & $0.49-1.92$ & 1.26 & $0.61-1.94$ \\
\hline Observations & 1192 & & 523 & & 523 & \\
\hline Samples & 7 Countri & & United $\mathrm{Ki}$ & ingdom & United $\mathrm{Ki}$ & ingdom \\
\hline
\end{tabular}

79 Notes: ${ }^{1}$ CRT $=3$ items in Gervais et al (2017); CRT $=7$ items in Stagnaro et al (2019). ${ }^{2}$ Political

80 orientation $=-3$ (very liberal) to 3 (very conservative) in Gervais et al (2017); Political

81 orientation $=-2$ (strongly liberal) to 2 (strongly conservative). Belief in God and Supernatural

82 Belief were measured on 100-point scales.

83

84 
85 Figure S1. Density plots of belief by sample from Study 1

86

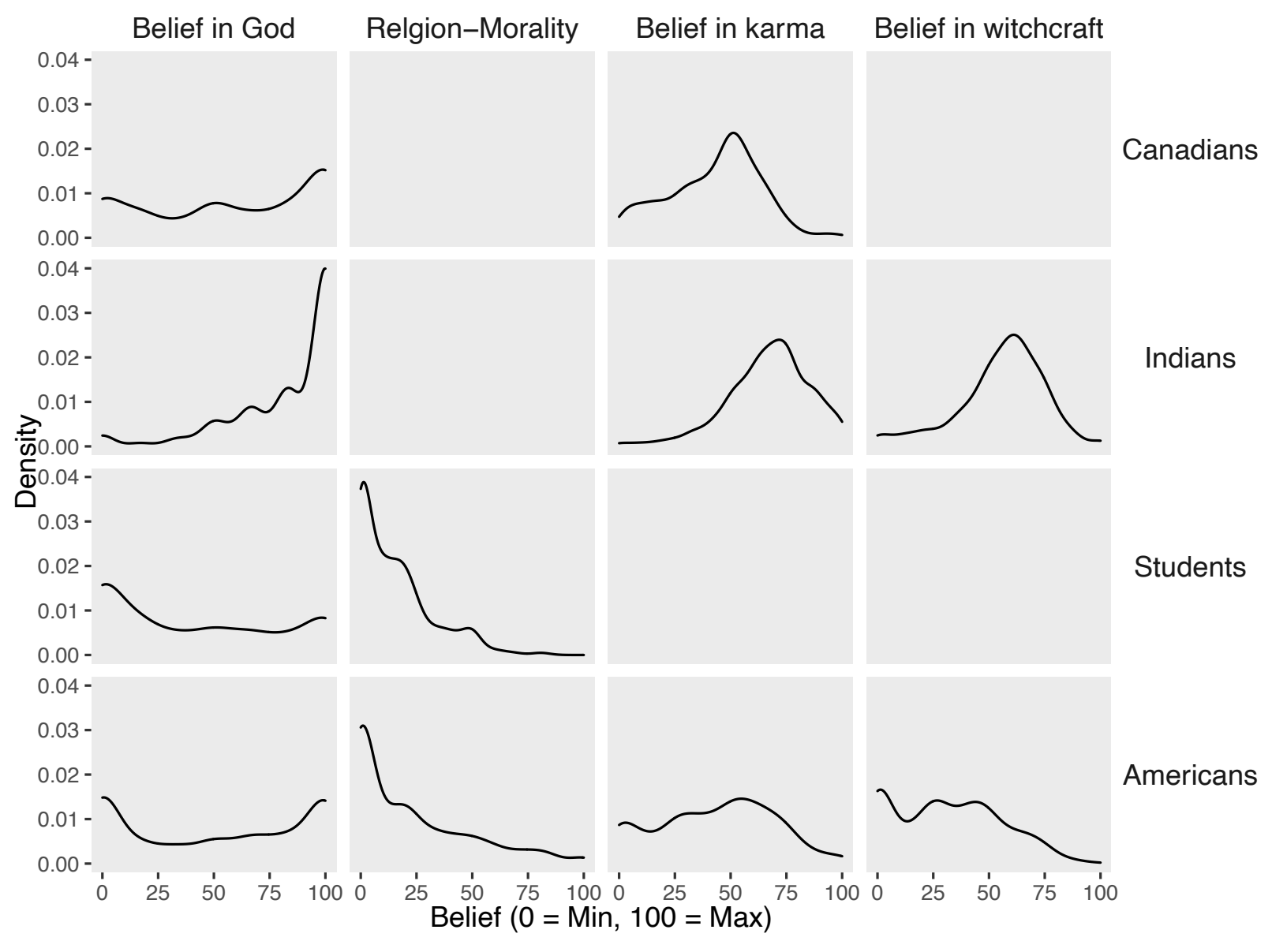


89 Figure S2. Density plots of belief by sample from Study 2

90
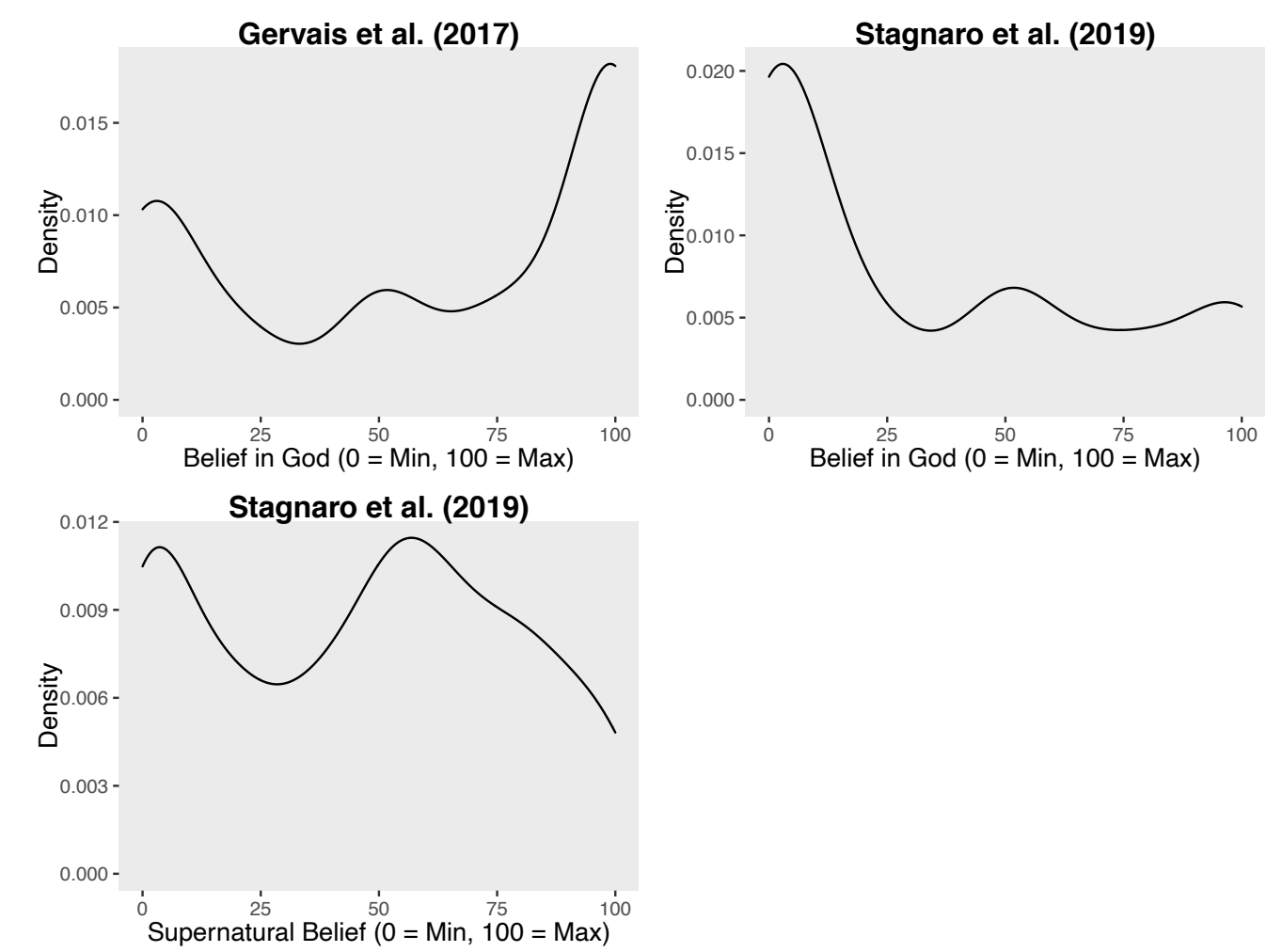
92 Figure S3. Correlation of belief in God and political conservatism in Gervais et al.'s (2017)

93 cross-cultural dataset

94

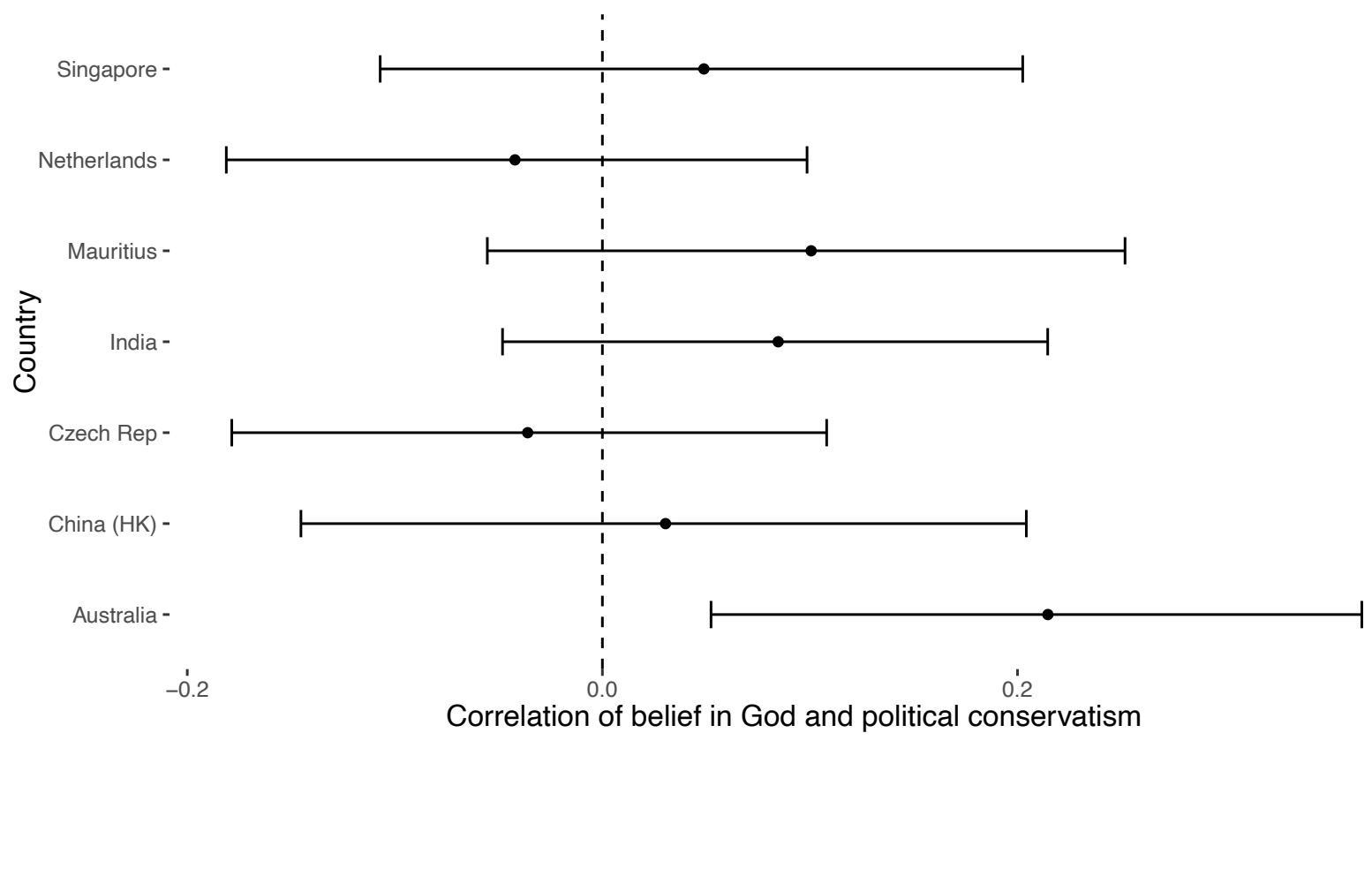

